\title{
ALGUNOS CONTEXTOS ARQUEOLÓGICOS URBANOS DE SARAQUSTA
}

SOME ARCHAEOLOGICAL URBAN CONTEXTS IN SARAQUSTA

\author{
Francisco JaVier GutiérReZ GonZÁLEZ \\ Universidad de Zaragoza \\ Arqueólogo
}

Resumen: Se presentan algunos conjun-
tos arqueológicos de viviendas y calles,
especialmente de época taifa del arrabal
meridional de Saraqusța, acompañados
de algunas reflexiones sobre urbanismo
andalusí, como procesos de saturación,
particiones de fincas o invasiones de la
calle por las construcciones particulares

Palabras clave: arrabal, arqueología, Saraqusța/Zaragoza, urbanismo, taifa.

\begin{abstract}
In this article several archaeological sites, which include domestic architecture and streets, mostly in the southern suburb of the Petty Kingdoms (Taifa) period of Saraqusta, are presented. The study is accompanied by some reflections on the urbanism such as the urban saturation processes in $\mathrm{Al}$-Andalus, the partitions of estates and the street invasions by the private constructions.
\end{abstract}

Keywords: Suburbs, Andalusi Archaeology, Saraqusța/Zaragoza, Urbanism, Petty Kingdoms period 
El urbanismo de la Zaragoza andalusí ha sido tratado desde la perspectiva del historiador (Canellas, Corral, Souto...), y desde el urbanista (Betrán), pero falta un estudio de conjunto reciente desde el punto de vista arqueológico, a pesar de los fundamentales trabajos de Pilar Galve. De los centenares de intervenciones realizadas en las últimas décadas sólo han sido publicadas una ínfima parte. Lo habitual es que queden en escasos informes preliminares archivados en el departamento autonómico competente, más allá de las escuetas noticias recogidas en los volúmenes de la revista Arqueología Aragonesa y alguna otra honrosa excepción. Es imprescindible que se impulse un estudio integrador desde el ámbito institucional, ya sea la administración autonómica o la universitaria, que saque conclusiones de la ingente cantidad de información almacenada en los archivos y museos. En este artículo pretendo llamar la atención sobre este tema y aportar un pequeño avance sobre algunos puntos de la ciudad, al tiempo que recuperar el tema arqueológico en esta revista. Han pasado ya 25 años desde que el equipo de arqueólogos municipales de Zaragoza publicó en Aragón en la Edad Media una primera revisión de los hallazgos de cultura material islámica obtenidos en nuestra ciudad. Allí trazaron un plano con cincuenta primeras localizaciones de restos más o menos importantes. Pilar Galve amplió este plano hasta un total de 140 entradas para el año 2005 (renumerándolas). Creo conveniente continuar con esta numeración al presentar nuevas intervenciones con la intención de que futuros estudios puedan dotar a su presentación de una más fácil consulta y descripción (Galve, 2009: 160 Fig.2). Sin embargo he desestimado intentar incluir todos los hallazgos andalusíes, trabajo más propio de una tesis y de una representación gráfica de mayor formato del que aquí se dispone. Además, lo habitualmente poco definitorio de las noticias referenciadas, les resta utilidad para el objetivo de este artículo. El listado, para las excavaciones tratadas aquí continúa así:

38. Calle Ramón Pignatelli, 71 (Escopetería): viviendas.

39. Calle Madre Rafols-Antiguo Cuartel de Sangenis (2002): viviendas. ${ }^{1}$ 40. Plaza Forqué s/n (2004): viviendas y calles. ${ }^{2}$

1 Según los informes depositados en la Dirección General de Patrimonio Cultural. Informe Preliminar. Excavación arqueológica Solar de la Plaza Jose $M^{a}$ Forqué s/ $n$, Zaragoza. Dos Volúmenes Expediente 096/03/2004. Del 19 de noviembre de 2004. Directores José María Viladés, Rosa Blanca González y Víctor Esteban. Firmado por José María Viladés Castillo.

2 Según el Informe Preliminar de la excavación arqueológica del antiguo cuartel de Sangenis en calle Madre Rafols s/n (Zaragoza). Fase I. Del 28 de diciembre de 2001.Dirigido por Blanca del Real y José Delgado. Firmado también por Rubén Peláez. Del 28 de diciembre de 2001. Los planos generales de esta intervención y la de la nota 1 han sido publicados, en un formato pequeño (Navarro Palazón, 2007: 80-81 y 113). 
47. Teatro Fleta: viviendas y calles. Posible basamento de torre.

53. Calle Cinco de marzo (patio de la Diputación Provincial-DPZ): viviendas y calles.

55. Calle Diego Murillo (antiguo cine Dorado): viviendas y calles. ${ }^{3}$

56. Paseo de la Independencia: viviendas y calles.

105. Teatro Romano y Calle San Jorge, 12-14: viviendas y balsa.

114. Catedral de La Seo.

137. Calle Sobrarbe, 37-41: viviendas.

141. Calle Mariano Gracia, 13: viviendas.

142. Calle San Miguel (Cine Goya): viviendas.

143. Calle Albareda, 18 (Hacienda): viviendas. Cerca de protección del arrabal. ${ }^{4}$

\section{Historiografía del urbanismo islámico 5}

Aunque algunos autores discrepan, no puede hablarse de una verdadera teoría urbanística en la organización de las ciudades musulmanas. El Islam realmente no formuló teorías sobre urbanismo como los clásicos, aunque afrontaron los problemas mediante cláusulas jurídicas y normas legales. Algunos corpus de jurisprudencia como el andalusí ««Kitāb al-Qadā» de Ibn alImām at-Tuṭ̂̄lī del siglo $\mathrm{X}^{6} \mathrm{y}$ el tunecino «Kitāb al-i’lān bi ahkām al-bunyān» de Ibn al-Rāmī» de Ibn Rami del siglo XIV ilustran estas reglas.?

3 Informe preliminar de la excavación de arqueológica en fase de ejecución del solar de calle Murillo s/n (Antiguo Cine Dorado) de Zaragoza. Del 19 de febrero de 2001, Director José Delgado Ceamanos. Y también el Informe de resultados de la excavación arqueológica realizada en el solar de la calle de Diego Murillo s/n (Zaragoza). Del 9 de abril de 2001. Directores José Delgado Ceamanos y Francisco José Navarro Cabeza.

Toda la información sobre excavaciones no publicadas ha sido recogidas de buena fe; si se detectase algún error u omisión yo soy el único responsable.

4 Según los informes depositados en la Dirección General de Patrimonio Cultural: Informe final de la excavación arqueológica del solar de la calle Albareda $n^{\circ} 18$ de Zaragoza ( $1^{a}$ fase). Del 28 de febrero de 2005. Directoras: Blanca del Real y Fabiola Gómez. Y también el Informe de resultados de la Segunda Fase de excavación arqueológica en el solar de la calle Albareda $n^{\circ} 18$ de Zaragoza. Del Informe del 18 de enero de 2006. Directoras: Blanca del Real y Fabiola Gómez.

5 Una aproximación a la evolución historiográfica puede consultarse en Navarro, Jiménez, 2007: 9-34.

6 Lo más interesante de esta obra, respecto a otras similares, es su intento de unificar toda la doctrina malikí sobre el tema (Van Staëvel, 1998).

7 Es un libro de proclamación de sentencias sobre construcción, algo así como un código general de la producción arquitectónica de 1314-1315 d.C. (Khiara, 1995). 


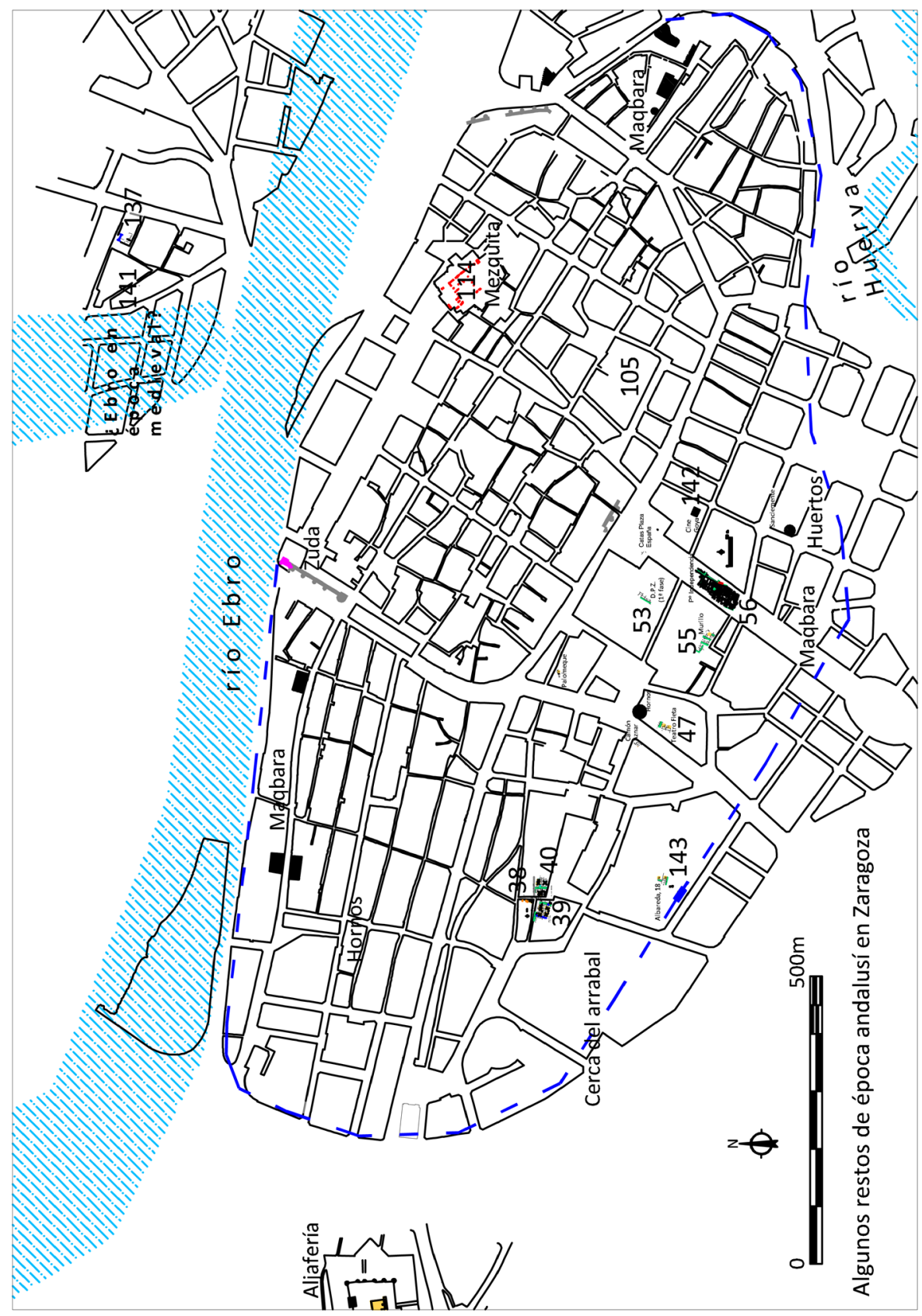

Figura 1. Algunos restos de época andalusí en Zaragoza 
Desde el siglo XIX la historiografía señaló el importante papel que jugaron la ley, la religión, las instituciones y las relaciones de parentesco del Islam como un sistema de reglas que ha de cumplirse en todos los aspectos de la vida; comparando la ciudad islámica con la ciudad occidental y creando el criticado «estereotipo inmutable» de la urbe caótica islámica. A esto contribuyó notablemente que hasta mediados del siglo XX no se tomase en cuenta los aspectos morfológicos de la medina islámica. Sólo entonces se subrayó la importancia del urbanismo anterior preislámico, del que es una continuación; no de la ciudad clásica, pues ya había decaído y cambiado su fisonomía durante la época tardoantigua. La centralidad está en la mezquita aljama y su entorno comercial, una zona pública con baños y madrazas; zona central que era conectada con las puertas mediante calle largas y rectas. En las zonas residenciales habría pequeños zocos sin especializar «de proximidad». Hacia fines del siglo XX se consensuó la consideración de una «ciudad islámica» configurada por el sistema político y legal - especialmente la diferencia de población según su relación con la Umma-, en barrios por etnias y religión; la segregación de géneros y la prevalencia de los derechos privados o comunitarios sobre los públicos. Guichard ha subrayado la interconexión entre el Estado omeya y la evolución de las ciudades de al-Andalus - en línea con la «ciudad gentilicia» propuesta por Garcin - (Guichard, 1998). En cambio, para Acién no puede hablarse de una ciudad gentilicia = tribal, como una fase de la ciudad islámica, pues la diferencia en este caso no es sólo entre formaciones sociales, sino en el modo de producción tribal/tributario. Así pues, «la evolución de la ciudad no la impone el Estado, ni la ciudad tradicional se debe a la ausencia de autoridad, porque la evolución que da lugar a la ciudad tradicional está regida por el fiqh - la 'ley islámica', la 'jurisprudencia', algo así como la 'inspiración divina del saber jurídico'- , y éste se basa en la hegemonía de lo privado que impone la ideología» (Acién, 2001, 18).

Punto fundamental en el estado actual de las investigaciones sobre la ciudad islámica es la introducción del análisis diacrónico en la investigación sobre las ciudades, punto clave para comprender los mecanismos de transformación del paisaje urbano. No obstante, dicha incorporación se ha producido en fechas bastante recientes, por lo que tradicionalmente, y hasta que esta inclusión se hizo efectiva, tanto la disolución de los modos de vida y topografía de los asentamientos clásicos como la aparición de la ciudad islámica han sido estudiados generalmente por separado. Ello propició el surgimiento de «una imagen de ciudad islámica o arabo-islámica casi como la negación misma del 
orden urbano» (Van Staëvel, 2001: 215), que sería protagonista de múltiples estudios «formulados desde perspectivas funcionales y acrónicas que apenas inciden en la evolución histórica de las ciudades andalusies y su relación con realidades urbanas anteriores»(González Gutiérrez, 2014: 202). A nivel práctico también se ha carecido de una visión diacrónica de los hallazgos arqueológicos reforzando una imagen estática de los espacios domésticos que termina por caracterizar antropológicamente las sociedades estudiadas (Gutiérrez Lloret, 2012: 140).

La relación entre derecho islámico y urbanismo constituye en la actualidad una de las líneas de investigación más fructíferas. Así autores como Van Staëvel confirman la actual comprensión de la ciudad islámica como «una ciudad vivida y fabricada en lo cotidiano por sus usuarios "desde abajo"», en línea con la defensa de la «hegemonía de lo privado» en la configuración de la ciudad. Sin embargo, la toma de decisiones de cada grupo humano al construir sus viviendas compartiendo medianeras, pozos de abastecimiento de agua..., no contradice para Acién la existencia de una intervención estatal u oficial en cuanto al planeamiento de murallas, redes de saneamiento y calles principales de «ortogonalidad» manifiesta y conscientemente planificada (Acién, 2001: 23-30).

En los últimos años Julio Navarro desde la arqueología y Javier GarcíaBellido y García de Diego desde la Coranomía han formulado teóricamente los principios en que se basan al aproximarse a las medinas medievales. Navarro y Jiménez han establecido una hipótesis interpretativa de génesis y evolución de la ciudad islámica. Este modelo clarifica la comprensión de la ciudad islámica, aunque no es estrictamente aplicable en todos los casos, especialmente en las ciudades con un urbanismo ya desarrollado al comienzo de la dominación musulmana, como la Zaragoza de comienzos del siglo VIII (Navarro, Jiménez, 2003: 324). Sin embargo, cada una de las partes de proceso de desarrollo urbano (densificación, saturación y desbordamiento), se encuentran presentes en todas las urbes; salvo, claro está, en aquellas que, por un motivo y otro, hubieran visto truncado su desarrollo. En Zaragoza, por ejemplo, la conquista cristiana en 1118 provocó que los arrabales no llegasen a desbordarse, si la cerca exterior estuvo donde se supone.

Por su parte, la Coranomía ha facilitado el estudio de las decisiones particulares de los privados y su influencia en el proceso de evolución urbana, especialmente en los procesos de densificación. Desde esta perspectiva Navarro defiende que son los pobladores construyendo sus casas los que generan el 
parcelario, a través de la adición de estancias y viviendas, la partición de casas en dos, la invasión del vial en planta o mediante la elevación en altura.

\section{Transformaciones urbanas en la Zaragoza Tardoantigua}

Los procesos de transformación, desde Siria al Magreb y al-Andalus, se produjeron en su mayor parte antes de la conquista islámica (Navarro, Jiménez, 2007: 37; Pinon, 2001). Es opinión generalizada que las principales características de este periodo son la debilidad del gobierno local, la decadencia del evergetismo privado, el éxodo al campo de las élites locales, la degradación de la ciudad clásica y su adaptación a un nuevo modelo urbano. Los siglos IV al VII sufren un proceso involutivo de los espacios urbanos: ruina de las infraestructuras de saneamiento, vertido generalizado de basuras, invasión de las áreas públicas por parte de edificios privados y amortización de los pórticos de las principales calles de la ciudad, reducción del perímetro de la muralla/ciudad; reaprovechamiento de materiales, aumento de los espacios vacíos intramuros... Un tejido urbano discontinuo que se concreta en torno a los centros religiosos e introducción de enterramientos humanos dentro del perímetro urbano. El trazado hipodámico decae y aumenta una fisonomía «orgánica» (práctica), por ejemplo, adaptando las calles al relieve topográfico. Tanto en la casa doméstica como en el paisaje urbano prevalece un proyecto menos exigente y más pragmático sobre la demanda de simetría y planeamiento rígido clásicos. En la Zaragoza tardoantigua ya habían sucedido cambios importantes - como el amurallamiento reduciendo el perímetro urbano-, cuando surgen los suburbia cristianos, del que el entorno cementerial de las calles Doset y San Blas y la iglesia de las Santas Masas serían principales ejemplos.

Alguna norma en ciudades mediterráneas de finales del siglo V imponía un mínimo de 12 pies entre casas para el ancho de las calles, lo que evidencia una voluntad de no renunciar a la propiedad pública en beneficio de los constructores privados, sino de establecer un mínimo intervalo con el objetivo de garantizar a la ciudad sus propios derechos. Más adelante veremos el profundo cambio de mentalidad con que se llegó a época islámica. La desaparición de la ortogonalidad en la ciudad tardoantigua fue un proceso largo en el tiempo, involuntario pero progresivo. Sin embargo en algunas ciudades como Conimbriga habrá voluntad de mantener cuando menos los ejes principales de la 
urbe, que también perviven en Écija o Mérida. El recrecimiento inicial de la pavimentación no transforma la orientación y el trazado de las vías pero, con los siglos, los procesos mencionados acabarán por colapsar las antiguas calles. Surgió así la necesidad de nuevas vías en una nueva ordenación que favorecerá la creación de los itinerarios de unión entre los nuevos polos de atracción de la ciudad tardoantigua (Alba, 2004: 422). En Zaragoza, el proceso debió afectar sin duda a buena parte de las calles menores pero, a juzgar por los relatos de fuentes islámicas, las vías principales debieron pervivir pues escribieron que sus calles eran anchas.

Los ejemplos de construcciones tardoantiguas en Zaragoza son escasos pero no cabe señalarlos ahora pues no es el objeto de este artículo. Sí son importantes para el periodo posterior las grandes elevaciones de la altura del suelo en algunas zonas, producidas con los vertidos de basuras domésticas y/o artesanales; además está constatada una considerable actividad de sobreelevación del terreno en la segunda mitad del siglo V d. C. (Escudero, Galve, 2012: 272-280). Cuando en época taifa el crecimiento y pujanza de la ciudad requiera de una gran actividad edilicia, deberá nivelarse estas capas de tierra. En las excavaciones arqueológicas este proceso se registra en potentes niveles de tierras con mayoritaria cerámica tardoantigua y escasos materiales andalusíes que, sin embargo, son los que fechan estos rellenos. En muchas zonas del interior de la ciudad se elevó el terreno hasta dos metros de altura (Aguarod, Mostalac, 1998: 83). Sin embargo, en zonas más periféricas de la ciudad como el patio de la DPZ en el n 8 de la calle de Cinco de Marzo-, la falta de esas acumulaciones de basuras y tierras hace que los restos califales o taifas incidan directamente sobre los restos romanos, favoreciendo la posibilidad de reaprovechar las estructuras clásicas como cimentaciones. En ese punto en concreto he comprobado la continuidad de la calle taifa sobre la alineación de la calle romana (Gutiérrez González, 2007: 369).

\section{Estructura genérica de la ciudad andalusí}

La ciudad islámica está estrechamente relacionada con su estructura y organización social. Una ciudad en la que sus habitantes son ante todo creyentes y el lugar de reunión natural es la mezquita y la vivienda es un santuario familiar (versículos 4 y 5 del XLIX del Corán). El recato que ayuda a mantener la igualdad de todos los musulmanes hace que las casas carezcan de fachada y no 
requieran ser visibles a los demás. El nuevo sistema cultural contenido en el Corán produce una reducción de las relaciones sociales. Por eso las ciudades musulmanas pierden la complejidad de las ciudades helenísticas y romanas. La ciudad se convierte en un organismo compacto cerrado por una o más murallas y dividido en varios recintos, en donde además cada grupo étnico religioso tiene su propio barrio; y el príncipe/gobernante suele vivir en una zona periférica en un edificio monumental que sirve de vestíbulo a toda la ciudad (alcazaba). La gran regularidad de las ciudades helenísticas y romanas es abandonada y ni siquiera hay una administración municipal que la imponga, sino que el gobernante de la ciudad es elegido directamente por el emir, el califa o el rey de la taifa. Ni siquiera las tiendas de los comerciantes se reúnen en una plaza, sino que se alinean en una o más calles que forman el zoco (Molina, 1992). El centro es la mezquita aljama pues no sólo es el centro religioso de la comunidad, sino también parte del poder político, centro de enseñanza, alojamiento para forasteros e, incluso, tesorería de la comunidad. En las excavaciones de la Seo zaragozana se halló un conjunto de feluses de comienzos del siglo VIII, lo que parece confirmar que desde el primer momento se otorgó gran importancia a este lugar (Hernández Vera, 1996: 75). La calle tiene una importancia secundaria porque la vida privada tiene más valor que la vida pública. La estructura de los barrios residenciales obedece a la tendencia a mantener el secreto de la vida familiar. Los espacios públicos y privados no forman zonas contiguas y separadas, como sucedía en la ciudad antigua, sino que existe un espacio público común, complejo y unitario. Un cinturón de huertas y almunias rodeaba la ciudad; sin embargo no hay estudios arqueológicos del entorno de Zaragoza, más allá de la reclamación de su importancia por parte de Carlos Laliena en alguno de sus trabajos.

Lo más habitual en las ciudades de nueva planta y en los ensanches residenciales debió ser una planificación parcial, en la que las disposiciones emanadas de las autoridades solían ser moderadas y se limitaban a lo que en términos modernos llamamos una macro-ordenación del espacio que incluía calles principales, mezquita, la sede del gobierno y frecuentemente las murallas. Si, por un lado, puede defenderse la continuidad de la ciudad paleoislámica, por otro también es necesario subrayar que la islamización terminó generando nuevas formas que sí permiten hablar de rasgos específicos en el urbanismo musulmán directamente relacionadas, por ejemplo, con el precepto religioso de la oración del viernes (Navarro, Jiménez, 2007: 67; Ídem 2007b: 266). Un lote de terreno preestablecido podía tener áreas no construidas que 
eran propiedad de las partes que lo integran, de manera que cuando llegasen nuevos pobladores, cada grupo puede acoger a sus familiares si les quedaba sitio o bien se instalaban en otro no ocupado. Por consiguiente, la morfología final de estas ciudades fue resultado de muchas decisiones a pequeña escala tomadas por los usuarios, quienes en última instancia fueron los que conformaron el parcelario, así como cierta parte del viario. El aspecto inicial es el de un hábitat disperso con huertos. Uno de los debates en las últimas investigaciones es entender si dentro de cada lote de tierras el callejero estaría o no planificado de antemano; si desde una autoridad superior se disponen estas calles interiores o si surgen como una necesidad de circulación entre las unidades colindantes y de común acuerdo entre los habitantes. Factores modificantes puntuales serían la topografía y los puntos de atracción como puertas, fuentes o las decisiones previas.

En Zaragoza, al comienzo de la época islámica, la existencia de una ciudad ya consolidada no propició una ordenación tal, sino que debieron reutilizarse las viviendas ya existentes y los espacios libres. En estos espacios las viviendas crecerían por adyacencia de estructura social arabo-islámica: la célula es la familia extensa patriarcal, de acuerdo a una organización social basada en clanes y tribus relacionadas con un linaje común. Las casas de los descendientes de un mismo antepasado quedarían idealmente agrupadas en torno a un patio común o a un mismo adarve (Guichard, Van Staëvel, 1995: 50). Por otra parte, el alto componente de población muladí pudo propiciar una variedad de soluciones de habitación. El resultado tras la adaptación a la múltiple casuística debió ser unas plantas de viviendas islámicas conformando unas manzanas y viario que la arqueología aún no ha logrado detectar en un conjunto lo bastante extenso dentro de la madina como para aportar datos significativos. ¿Por qué? La escasa cantidad de hallazgos islámicos en el interior de la ciudad amurallada, especialmente en relación a los hallazgos romanos, puede tener varias explicaciones. Por un lado, la supuesta alternancia de espacios construidos con espacios abiertos en reserva o huertos urbanos, hace difícil estar seguros del porcentaje de espacio habitado. Por otra parte, las cimentaciones de las siguientes etapas históricas las hayan eliminado, en especial desde mediados del siglo XVI.

Sin embargo, en los arrabales, tanto al norte del Ebro - donde la ocupación islámica llega hasta la calle Villacampa [Figura 1.137, 141] —, como especialmente al sur y suroeste de la ciudad, la escasa ocupación romana y tardoantigua no elevó el terreno y hubo escasas construcciones en época bajo- 
medieval. Sólo bien entrada ya la época moderna, grandes y profundas obras incidieron en la mejor o peor conservación de los restos residenciales andalusíes. Especialmente feliz fue la coincidencia de que sobre los restos hallados en el paseo de la Independencia confluyesen los límites de tres parroquias en época bajomedieval y moderna, lo que debió reducir las obras en esta zona (García-Terrel, 1999). Esto, unido a la creación del propio paseo de la Independencia en el siglo XIX, nos permitió hallar una gran superficie conservada de arrabal. Por contra, la compartimentación del casco antiguo de Zaragoza en pequeños solares propicia una mayor destrucción de los restos andalusíes durante los siglos siguientes y que las excavaciones arqueológicas tengan más dificultades en detectarlos. La mitad de esos primeros cincuenta hallazgos citados del artículo de 1991 eran sólo pozos sépticos, lo que da una idea de lo difícil de la detección de los muros y suelos; así como del alto porcentaje de destrucción posterior que sufrieron, pues esos pozos suelen ser sólo detectados ya en la franja de ocupación antigua a la que perforan.

\section{Evolución urbana de Saraqusța}

Los restos publicados de esta etapa emiral son escasos en Zaragoza. ${ }^{8}$ Tenemos escasos niveles de habitación y algunos pozos sépticos, como en el solar del Teatro romano; y más abundantes ejemplos de «fosas sépticas» o grandes basureros. En los últimos años se ha aceptado la explicación de que estos basureros corresponden al necesario relleno posterior a la extracción de árido empleado en la construcción de los tapiales de las casas que, una vez concluida la edificación, necesitan ser colmatados para servir de suelo. Pero el porcentaje de pozos sépticos emirales es mucho menor si lo comparamos con los pozos de época califal o taifa. Como ejemplo, la datación de los materiales cerámicos de los pozos sépticos de época andalusí hallados en la catedral de La Seo, durante las campañas dirigidas en los años noventa por José Antonio Hernández Vera, sólo ha proporcionado un ejemplo emiral, mientras que los califales y taifas han supuesto un total de dieciocho pozos - de los que cinco

8 En la cercana Lérida los restos emirales hallados en el Antiguo Portal de Magdalena parecen indicar para sus excavadores que desde un principio se tiene muy clara cuál será la máxima área ocupada, definiéndose sus límites, los viales y las manzanas; hechas prácticamente de una sola vez y organizada desde instancias públicas (Loriente, Gil, Payà, 1997; García Biosca, Giralt, Loriente, Martínez, 1998). En el arrabal cordobés de Šaqunda se considera probada una planificación general previa, tanto de «los ejes viarios principales, como la ordenación general de la trama urbana» (Casal, 2008: 133). 
son califales y ocho de época taifa, mientras que otros cinco no proporcionaron materiales adecuados para diferenciarlos entre estas dos etapas-, (Gutiérrez González, en prensa-b). Cabe preguntarnos si podría trasladarse esa estadística de forma fiable a la cantidad de población de las sucesivas fases históricas en toda la ciudad, si se pudiese aplicar a una extensión mayor y mejor distribuida.

Será a partir de la segunda mitad del siglo $\mathrm{X}$ cuando se producirá una evolución del hábitat hacia una mayor estructuración y planificación y de ese periodo los vestigios arqueológicos son más numerosos. Se producen cambios en los viales, notables elevaciones del terreno y se aprecia también gran actividad de construcción de viviendas (Galve, 2009: 161). A pesar de todo ello, en las distintas aproximaciones al urbanismo de la Zaragoza andalusí se ha defendido la continuidad del trazado clásico durante el periodo islámico (Almagro, 1987, Corral, 1998 y 2008, Betrán, 2005). Parece muy probable la idea de una medina implantada sobre la vieja planta romana, junto a una importante transformación de las zonas externas a la muralla. Salvo modificaciones en alineaciones, estrechamiento de calles y adarves, el caserío encerrado en el interior de la muralla no sufrió grandes modificaciones (Galve, 2009: 161). Almagro ya definió la planta de Zaragoza como un «modelo totalmente atípico», en la que la reutilización de las estructuras de origen romano es algo habitual, distinguiéndose de la mayoría de ciudades andalusíes; ya que lo habitual es lo contrario y que podamos «considerar a las ciudades que se consolidan entre los s. IX y XI, como ciudades nuevas, con independencia de que sean creaciones ex nоио o continúen en la misma ubicación de ciudades antiguas» (Acién, 2001: 23). La escasez de evidencias arqueológicas publicadas sobre la madina zaragozana, especialmente en lo que atañe a la red viaria, no permite rebatir ni afirmar desde la arqueología esta excepcionalidad de Saraqusta. Parece evidente que la continuidad Este-Oeste de los viales calle Manifestación, calle Espoz y Mina y calle Mayor debe ser la perduración de un decumano romano; y que la calle Don Jaime I sería el cardo de Caesaraugusta, antes de ser truncado en su parte sur en un momento aún no concretado. ${ }^{9}$

Las citadas descripciones de Saraqusța realizadas por Galve, Corral y Betrán cubren todos los aspectos conocidos hasta la fecha y no tiene sentido aquí repetir lo allí ya expuesto, aunque «los estudios en profundidad, e incluso en 
noticias, son tan escasos que, tras tantos años de trabajos arqueológicos en el Casco Histórico, es imposible elaborar una síntesis medianamente razonable en el momento actual» (Galve, 2009: 158).

Comenzando un breve repaso a las características principales de la ciudad, hablaré de que en al-Andalus son excepción los ejemplos en que no hay amurallamiento; algo que continuará en época plena y bajomedieval (Lafuente, en prensa). Siempre que la topografía lo permitió hubo previsiones de crecimiento que dejaron amplias zonas vacías en la periferia del núcleo habitado. Habitualmente se había considerado alfares y cementerios como establecimientos supuestamente periurbanos sin reparar en que se emplazaron dentro de la medina y sólo con el tiempo y la saturación esas construcciones se vieron obligadas a salir extramuros. En la intervención arqueológica en el solar del número 18 de la calle Albareda [Figura 1.143] se documentó un muro o zócalo de cantos rodados trabados con tierra, asociado a dos fosos en $\mathrm{U}$ paralelos, que ha sido interpretado por sus excavadoras como el muro de tierra que cerró los arrabales en este punto de la ciudad..$^{10}$ La confirmación arqueológica del $\mathrm{ra}$ dam o muro de tierra de protección del arrabal - a falta de la publicación científica de los datos que confirme la cronología andalusí y no cristiana de la amortización de los dos fosos-, es una visible muestra de esa previsión de espacio para el crecimiento que se preparaba en las ciudades islámicas; de la que tenemos varios ejemplos como Calatayud, Daroca, Barbastro, Jaén o Mallorca (Corral, 1987: 40; Navarro, Jiménez, 2007: 79; Riera, 1998: 217). Sin embargo, en esos informes preliminares no se hace referencia al hallazgo de ningún nivel de construcción de la cerca, por lo que no tenemos datos sobre el momento de su construcción; sobre la época en que los habitantes de la ciudad o el gobernante de al-Andalus decidieron proteger tan amplio espacio. La ausencia de hallazgos del muro defensivo en otras intervenciones puede deberse a una simple falta de coincidencia con su trazado y a sus endebles características. En otras ciudades como Murcia tampoco se conocen los muros de tierra porque las cercas de los siglos XII y XIII los ocultaron. En nuestra ciudad quizá el muro que lo ocultó fue el cristiano de réjola; algo que la arqueología deberá comprobar. Por otra parte, si la amortización del muro de tierra islámico se produjo en el siglo XII con la conquista cristiana - tal como parece

10 Blanca Del Real y Fabiola Gómez, Informe de resultados..., 2006 (inédito). Los dos fosos tienen 4 metros de achura, con dos metros de profundidad conservada; mientras que del muro de cierre se conservaban 1,20 m de altura. 
Francisco Javier Gutiérrez González

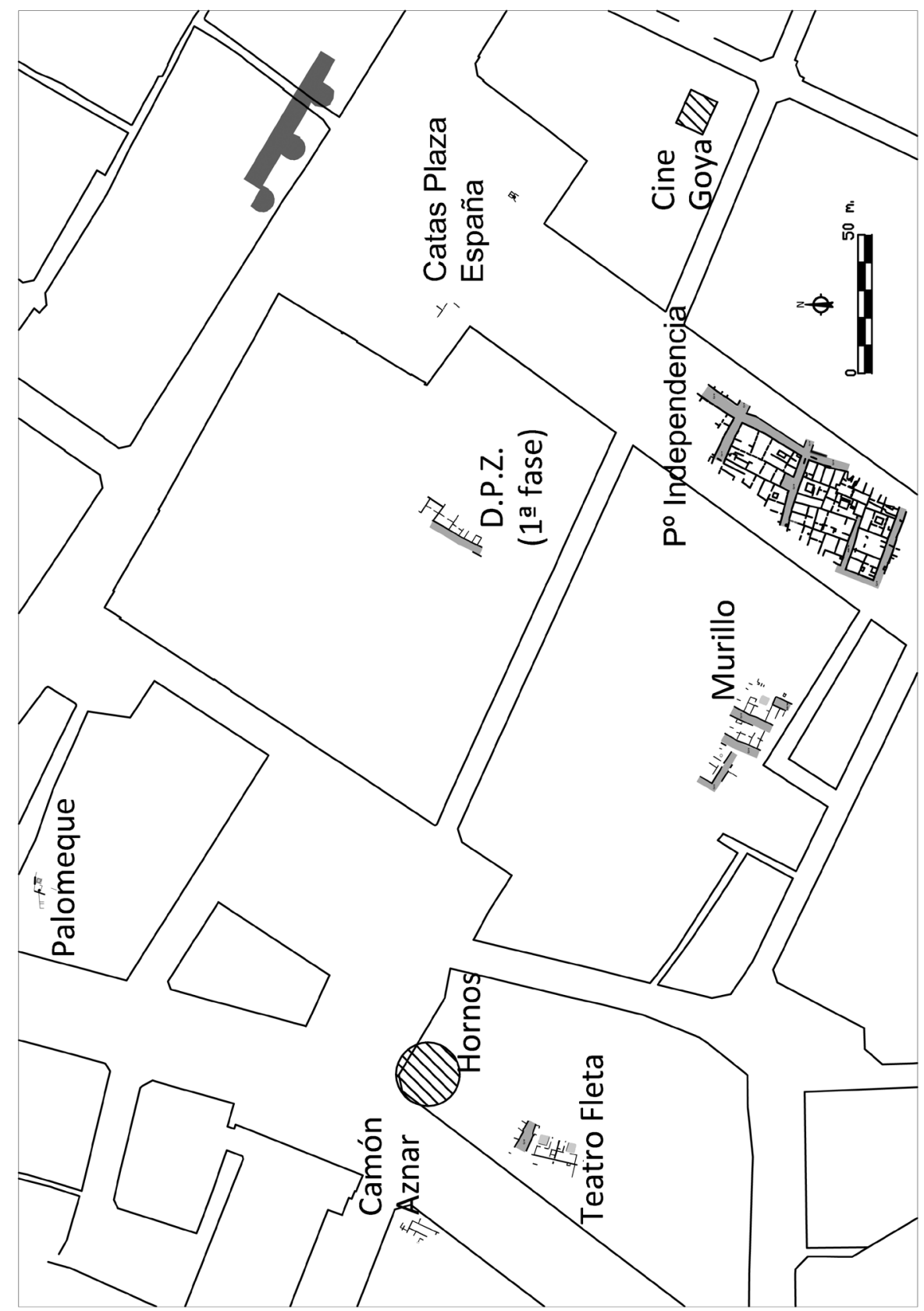

Figura 2. Algunos hallazgos en el arrabal meridional 
evidenciarse de la excavación del $n^{0} 18$ de la calle Albareda-, hay que preguntarse dónde se encontraría el muro de réjola cristiano en esta zona, pues no se halló rastro alguno en esa intervención. Quizá fuese destruido en el siglo XVI al construirse el Hospital de Convalecientes; obras que sí eliminaron parte de las viviendas taifas cercanas, por lo que no pudo comprobarse si sus muros exteriores formaban parte del sistema defensivo. En la colección diplomática de la orden de San Juan de Jerusalén, se cita la existencia de la Puerta de Sancho ya en 1180; aunque la noticia no nombra explícitamente el muro, lo razonable es pensar que había una cerca (Ledesma, 1967: 231).

En cuanto a las necrópolis o maqābir (singular maqbara), en Zaragoza las encontramos fuera de la muralla de piedra, por lo que podemos suponer que la densidad existente al comienzo del dominio musulmán no debió permitir instalarlas en su interior. Pilar Galve ha tratado las necrópolis islámicas medievales en varios trabajos, citados en el apartado bibliográfico final; investigaciones en las que se consiguió una fecha absoluta del siglo VIII para un enterramiento de la calle Predicadores, lo que abunda en la idea del establecimiento del área cementerial islámica fuera de la ciudad romana y, precisamente, sobre la zona ocupada por la necrópolis romana occidental hasta el siglo IV. En las zonas vacías situadas en la periferia del caserío habitado hubo también un cinturón perimetral hortícola anexo a la cara interna de la cerca, que permitía el sustento en épocas de inseguridad. Los niveles de tierras halladas en la excavación de la calle Sanclemente parecen confirmarlo en este punto (Escribano y Mostalac, 1998: 83). Así pues, en Zaragoza, el escenario propuesto para una ciudad islámica de agrupaciones de casas dispersas conviviendo con espacios extensos no edificados, que incluyeran cementerios y huertos - zonas cuyo origen son las previsiones lógicas de crecimiento efectuadas cuando trazaron las defensas fundacionales - , sólo tendría lugar en los arrabales taifas. Tan sólo cuando comienza a saturarse el espacio urbano, cementerios, instalaciones artesanales y huertos son expulsados paulatinamente hacia la periferia. La conquista cristiana abortó pronto en Zaragoza esta evolución que sí comprobamos en otras ciudades meridionales de al-Andalus.

El siglo X vio un progresivo crecimiento de la población y actividades de la ciudad, en consonancia con su función de capitalidad de la Marca Superior y el desarrollo de la producción agrícola del entorno. Por el momento no se ha definido convenientemente para Zaragoza una evolución de la cerámica entre el siglo X y el XI que ayude a distinguir muchos de los hallazgos; así como la perduración de los materiales de talleres islámicos que se utilizó en Zaragoza 
durante el siglo XII, incluso tras la conquista cristiana. En trabajos anteriores he intentado aportar algo sobre esta cuestión (Gutiérrez González 2006: 141 270, 2007, 2009; Gutiérrez González, De Miguel Millán, 2009; Ortega Ortega, Gutiérrez González, Pérez-Arantegui, Déléry, 2013).

Cuando el crecimiento de época taifa hace que se planteen los trazados de los arrabales residenciales, como los hallados bajo el paseo de la Independencia [Figura 1-56] y la Plaza José $\mathrm{M}^{\mathrm{a}}$ Forqué [Figura 1.38, 39, 40], este proceso parece tener lugar efectivamente, y quizá por vez primera en Saraqusta, combinando la planificación parcial de calles principales con la definición privada del detalle de las manzanas.

Betrán, al opinar sobre un informe provisional sin haber concluido la excavación, cree que en la Manzana 1 hallado bajo el paseo de la Independencia hubo doce parcelas originales, que se transformaron en quince (Betrán, 2005: 68 nota 105). Lo cierto es que en las escasas zonas en las que pudo excavarse por debajo de los niveles de fundación de las viviendas taifas, no detectamos niveles anteriores que fuesen reformados y que transformasen la distribución de la manzana taifa; si bien es posible que se produjese esa compartimentación. La prohibición de la Dirección General de Patrimonio Cultural del Gobierno de Aragón de continuar la excavación de estas viviendas - y su consiguiente eliminación-, en aras de su conservación, impidió comprobar si existió realmente esa evolución. La distribución de la Manzana 1 está condicionada a que las tiendas se abran a la calle principal. Las distintas estancias de la zona noreste de la manzana no tienen espacio para ser casas; además, de ser viviendas hubieran buscado más discreción. En cuanto a la manzana norte - la denominada número $2-$, Betrán supone que «en fecha posterior se formó un adarve privado para dar acceso desde la calle pasante septentrional a una pequeña parcela enclavada en la zona central de la manzana» (Betrán, 2005: 68). Esta explicación es errónea, comprensible al no tener los datos concretos. En la monografía sobre esta excavación ya aclaré que en realidad es un espacio semiprivado, un fina ' ' (pl. afniya) abierto alrededor o a lo largo de un edificio. Nunca hubo un cierre del espacio comprendido entre las viviendas números 16,19 y 20 , sino que permaneció abierto a la calle, ya configurado en el planteamiento inicial de dicha manzana. Las funciones a las que se destinase en concreto esta zona sin construir podrían ser desde lugar de reunión, para la venta ambulante, zonas para carga o descarga de bultos desde las caballerías, hasta áreas de manufactura de productos que serían vendidos en las tiendas cercanas que se disponen en pequeñas habitaciones en el exte- 
rior de la manzana y especialmente junto a la arteria de mayor tránsito en esta zona (Gutiérrez González, 2006, 55-56). Estos afniya son considerados por los vecinos como un espacio semiprivado, poseído colectivamente. Betrán resumió claramente el concepto de propiedad de suelo «... en la ciudad islámica, a diferencia de la cristiana, cada poblador compra el suelo que se pueda permitir, sin limitaciones, de modo que se convierte en pleno propietario de la parcela, sobre la que edifica hasta donde le permiten sus posibilidades. De este modo, no existe nada parecido a un propietario único del suelo, ni una propiedad conjunta de suelo de uso público y de uso privado; no existe tampoco una planificación previa que se inmiscuya en los reconocidos derechos individuales producto de la propiedad plena, ni unos mecanismos jurídicos que permitan controlar el desarrollo de la edificación y de preservar el espacio público. De acuerdo con el concepto de la umma - 'la comunidad islámica' - , no se concebía la idea de un interés público con una personalidad propia, limitándose las raras intervenciones de la autoridad en el proceso constructivo de la ciudad a mediar para resolver enfrentamientos entre los distintos derechos individuales, más que a defender un desdibujado derecho público (...)» (Betrán, 1996: 399 nota 31). Sin embargo, el mismo autor apuesta, a tenor de los hallazgos del paseo de la Independencia y plaza Forqué, por una «planificación geométrica de trama viaria ortogonal» (Betrán, 2005: 62).

Este es uno de los debates actuales entre los especialistas ¿La ciudad se organiza desde la autoridad o la generan los habitantes con sus construcciones? Personalmente me inclino por la coexistencia de las dos realidades. En el caso zaragozano la autoridad organizaría las vías principales - por otra parte ya existentes al comienzo de la etapa islámica desde época romana-, así como el reparto de lotes de tierras a nuevos grupos de recién llegados a la ciudad, la implantación de la mezquita mayor, los baños públicos y el sistema defensivo. Hay ejemplos en todo al-Andalus que cuesta comprender sin la planificación desde el poder como, por ejemplo, algunos arrabales de Córdoba, si bien es cierto que la intervención del califa en la capital sería seguramente mucho mayor que en otras ciudades (Murillo, Castillo, Castro, Casal, Dortez, 2010: 604). Sin embargo, en la mayor parte de la ciudad será la actividad edilicia particular la que genere el parcelario y las calles.

En el resto de actividades son los propios habitantes los que de común acuerdo construyen sus viviendas asignando las superficies de las viviendas y compartiendo muros medianeros. Es preciso decir aquí que no puede hablarse en propiedad de ortogonalidad en la mayoría de las ciudades de al-Andalus, 
que también menciona Corral para Zaragoza junto a «un urbanismo muy compacto y perfectamente planificado» (Corral, 2008: 208) y Betrán que califica de «planificación isodómica» al arrabal (Betrán, 2005-b: 83 nota 26); sino más bien de trazado con tendencia a la regularidad. Regularidad que unos lo interpretan como decisión del gobernador de la ciudad o del príncipe: Corral habla de un «claro diseño urbano propiciado por una autoridad pública» y Betrán de «una intervención directa o indirecta del Estado antes que en la autogestión de grupos preconstituidos» (Betrán, 2005-b: 83 nota 27). Mientras, otros lo atribuyen a una «regularidad orgánica» generada por la coherencia geográfica o geometría natural del espacio o por la existencia subyacente de un proyecto previo de carácter agrícola (parcelación, irrigación y drenaje). Una voluntad planificadora no obligatoriamente ajena a la comunidad campesina, pues la propia organización de los procesos de trabajo agrícolas demanda formas geométricas. En sus trabajos sobre Murcia, Navarro y Jiménez han rastreado la perduración del parcelario agrícola romano en el actual de la ciudad (Navarro, Jiménez, 2007: 97; Ídem, 2003: 354-357). En otro artículo he llamado la atención sobre las aportaciones mutuas de conocimientos entre los hallazgos romanos y medievales, si bien el trabajo está pendiente para Zaragoza pesar de sus posibilidades (Gutiérrez González, 2007: 365-371). En los arrabales del sur de Saraqusța - la zona que hoy día mejor conocemos de la ciudad medieval-, la expansión de la ciudad andalusí se produjo sobre unos terrenos ya ocupados. ${ }^{11}$ El espacio ya había sido organizado, hasta cierto punto en época romana, pues tanto bajo el paseo Independencia como en el antiguo cuartel Sangenis se han documentado enterramientos de época romana. En el momento de extender las zonas residenciales sobre esas zonas - durante el califato y, especialmente hacia el inicio de la taifa - , ya existirían elementos agrícolas o artesanales y algo de hábitat disperso, más denso conforme más cerca se encontrase de la madina; tal y como se refleja en la densa ocupación califal bajo el patio de la DPZ, los dispersos restos encontrados bajo el paseo Independencia y la ausencia de elementos inmuebles residenciales de época califal tanto en el Teatro Fleta como en la plaza Forqué (Gutiérrez González, 2006: 279-297; Ídem, 2007: 357-360; Ídem, 2009).

11 De forma similar a como se ha comprobado para otras ciudades de al-Andalus, por ejemplo para Córdoba: «La red viaria (...) parcialmente heredada de época romana, tuvo una especial relevancia tanto para la articulación de los arrabales (...) y tejiendo una red jerárquica con el viario que, partiendo de ellos, estructuraba los diferentes barrios» (Murillo, León, Castro, Casal, Ortiz, González, 2010: 543). 
El resto de las excavaciones, que he podido conocer y que han proporcionado restos de calles, no permiten por el momento extraer especiales conclusiones, debido a su escaso tamaño y a la distancia entre ellas. Caso excepcional y aún por estudiar es la intervención en la calle Diego Murillo (antiguo cine Dorado) en la que en $683 \mathrm{~m}^{2}$ excavados se documentaron cinco tramos de viales - cuatro en dirección norte-sur y uno en dirección este-oeste-, que ocupan hasta $155 \mathrm{~m}^{2}$, con anchuras de entre 2,50 y $2,90 \mathrm{~m}$ para las calles. Según apunta su excavador no se trata de reformas del parcelario, pues los muros perimetrales permanecen inalterados en las tres reformas constatadas en las viviendas. Quizá deba pensarse en una zona de casas-taller de reducidas dimensiones que generasen manzanas también de escaso tamaño.

Lo que sí parece confirmarse son las diferencias entre las calles de los «distintos arrabales» del sur de la ciudad. En las calles halladas bajo el paseo de la Independencia o el antiguo Cine Dorado de la calle Murillo, no se incluyeron canalizaciones que desagüen las aguas residuales, utilizándose habitualmente pozos ciegos. Pero más extraño es que ni siquiera se canalizaron las aguas pluviales, que en Zaragoza alcanzan momentos puntuales de carácter torrencial. Como mucho, en la calle principal norte-sur bajo el paseo de la Independencia que conectaría la madina con la Iglesia de las Santas Masas, se preparó el subsuelo del vial excavándolo en una «U» abierta para alejar las aguas de los muros de las viviendas. Embebida en el muro exterior perimetral de la vivienda 23 de la Manzana 6 hallamos un atanor que sirvió de bajante de pluviales para su evacuación a las un pozo excavado en la calle (Gutiérrez González, 2006: 54 y 121-126). En cambio, en el entorno de la plaza Forqué sí se instalaron canales para evacuar aguas pluviales de hasta medio metro de ancho y metro y medio de altura, simplemente excavadas en las compactadas gravas naturales. ${ }^{12}$ Sólo queda esperar que futuras intervenciones indiquen el camino a una explicación convincente a esta diferencia, ya sea por grupo tribal, económica, topográfica, temporal o cualquier otra.

En cuanto al abastecimiento de agua potable «se hacía mediante un equilibrio entre las iniciativas de los individuos, que aseguraron ellos mismos el abastecimiento de su casa y gestionaron las estructuras hidráulicas de su barrio, y las intervenciones de las autoridades políticas, que se preocuparon primero del

12 Aunque sus excavadores las interpretan como 'cloacas' de evacuación, parece una idea poco sostenible, según los datos aportados en el informe preliminar como la ausencia de cualquier revoco aislante que hiciera practicable su utilización como cloacas. 
abastecimiento de sus palacios, y luego del bien común, al abastecer la mezquita aljama y al acondicionar varias fuentes (Mazzoli-Guintard, 2014: 99). Algo más adelante continua «Les particuliers ont assuré eux-mêmes l'approvisionnement de leur maison, au moyen d'un puits, en recueillant les eaux pluviales ou en payant les services d'un porteur d'eau» (Mazzoli-Guintard, 2014: 127). En el paseo de la Independencia detectamos dos pozos que llegarían al freático y que servirían como pozos de agua semipúblicos, a juzgar por su localización accesible. Hay que recordar que, teóricamente, se consideraba que todo el mundo tiene derecho de beber o abrevar sus animales en las aguas públicas y que el dueño de una propiedad colindante con estas aguas debe permitir el acceso libre a ellas y soportar esta servidumbre de paso (Vidal Castro, 1995: 99). En el resto de solares aquí estudiados se han documentado otros pozos que pueden aportar algún dato sobre su densidad en relación a las viviendas existentes, aunque son muy escasos para pensar en realizar un estudio estadístico.

En otras ciudades de al-Andalus se ha comprobado que la localización del inicio de los arrabales está ligada a la de almunias previas de élites urbanas; sin embargo hasta ahora tampoco se ha identificado ninguna de estas edificaciones en nuestra ciudad que provocase el surgimiento de algún arrabal.

\section{Procesos de evolución de la ciudad}

Según las reglas morfogenéticas, la densificación provoca, además de la edificación de zonas libres, la invasión de la calle y la subdivisión de fincas, las cuales compensan el espacio perdido creciendo en altura. Como veremos más adelante en ejemplos zaragozanos, esa necesidad de espacio provoca que se creen viviendas en el interior de la manzana y se genere un adarve de acceso a su interior. La densificación provoca también el estrechamiento de las calles y la edificación en espacios antes libres como huertos y jardines privados (García-Bellido, 1998 y 2000). La expansión sobre terreno reservado vacío sucede con un trazado regular, según Navarro y Jiménez por continuidad del parcelario rústico precedente (caminos de acceso y acequias de riego), que se organizan con una regularidad práctica. La expansión sobre pequeños espacios vacíos del caserío está condicionada por el caserío preexistente, por lo que las viviendas y calles se adaptan y pierden regularidad. Esto hace que en las excavaciones urbanas de pequeños solares no puedan detectarse fácilmente elementos regulares o identificar los distintos espacios de las viviendas. A esto se añade el hecho, comprobado arqueológicamente, de que muchas vi- 
viendas andalusíes reaprovechan las cimentaciones romanas que encontraban; se produce así una continuidad de orientaciones de muros de casas tras un hiato temporal de varios siglos..$^{13}$

\section{Procesos de saturación}

La ciudad, conforme va creciendo en población, sufre una densificación del hábitat que provoca nuevas construcciones sobre espacios vacíos y en reserva. El proceso de crecimiento y densificación de la manzana puede suceder en la ciudad al mismo tiempo tanto de forma centrípeta - desde el perímetro de la manzana que da a las vías públicas hacia el interior-, como de forma centrífuga - por adición de células domésticas. «Este último parece el más apropiado en áreas completamente libres de construcciones y servidumbres, mientras que el primero parece que debió ser más frecuente cuando preexistían camino que habían de ser respetados y que acabarían por convertirse en vías públicas» (Jiménez, Navarro, 2000: 89). En el antiguo Cuartel Sangenis [Figura 3] se observó que la parcela interior de la manzana (Casa 5), se construyó con unos materiales de calidad inferior a la del resto de casas; lo que quizás apunta hacia esa evolución de la parcela: que la Casa 5 fuera la última edificada, sobre un terreno interior de la manzana en reserva.

También en la plaza Forqué, en las dos intervenciones concluidas en 2002 y 2004 - aún estando pendiente la estudio la primera (antiguo Cuartel Sangenis) y en proceso la que hemos empezado a realizar sobre la de 2004-, observamos esa densificación del hábitat que requiere, ante la falta de espacio consecuente, de una fragmentación de las parcelas para albergar a los nuevos núcleos familiares resultantes. El proceso de partición de fincas por herencias suele producirse de dos formas, según el tamaño de parcelas: en las grandes - posiblemente diseñadas desde su construcción para acoger familias extensas -, se crean dos patios que se reparten entre las dos nuevas casas; mientras que las pequeñas se dividen con un muro medianero, que crea la sensación de una simetría entre las dos nuevas casas que no fue realmente buscada. ${ }^{14}$

13 En otras ciudades como Jaén también se ha documentado estos reaprovechamientos (Salvatierra, Serrano, Pérez, 1998: 205).

14 Esta partición que la encontramos en el palacio de calle Fuensanta y calle Organistas de Murcia, y quizás en Pla d'Almatá en Balaguer o El Fortí de Denia. García-Bellido y García de Diego explica que el «sistema de donaciones y herencias islámicas que, lejos de mantener el bien inmueble heredable indiviso para su máxima rentabilidad, desarrolla un sofisticado cálculo aritmético de particiones fraccionarias y quebrados según las relaciones familiares de primero o segundo grados de descendencia 
En la plaza Forqué también podemos apreciar dos posibles ejemplos de particiones de viviendas. ${ }^{15}$ En la excavación de 2002 (la más occidental), la vivienda inicial situada al noreste del solar se ha subdividido en dos casas más pequeñas mediante la interposición de un medianil norte-sur que partió en dos el patio de la vivienda. La que quedó más al oeste parece haber añadido una tienda que se abriría a la calle con dirección este-oeste situada al norte. En el Informe preliminar sus excavadores señalan que los dos patios localizados en esa Casa 2 están unidos por una puerta de la que han quedado conservadas en el umbral las gorroneras de encaje. Es tentador pensar que, en realidad, la partición de la finca para albergar a una nueva unidad familiar generase dos viviendas distintas que, a pesar de todo, mantuvieron una vía de comunicación a través del patio aunque, más bien, funcionase habitualmente como una separación permaneciendo cerrada. Por otra parte, quizá haya otra explicación a estos dos patios y es la norma de separación estricta de las mujeres que fomentó en las viviendas grandes el desarrollo de un sistema de «doble circulación» o de la división de la casa en dos zonas; una reservada a las invitados hombres y otra las mujeres y miembros de la familia (Youssef Hoteit, 1993: 41). Esta diferenciación en las casas pequeñas se conseguiría verticalmente llevando a la mujer a al piso alto. Sin embargo, otro detalles me hacen decantarme por la separación en dos viviendas. Primero, que en las casas 1, 3 y 4 los pozos de agua estás situados en el centro del patio, mientras que en la subdivisión oriental de la Casa 2, hay un segundo pozo en una situación distinta, adosado al muro y con una estructura aneja, posiblemente recogiendo aguas pluviales. Además, se localizó una puerta tapiada que daba a la calle de dirección nortesur a mitad de la fachada este de la Casa 2; seguramente la entrada original a la vivienda, que fue cegada para llevar los accesos a la fachada norte, desde la calle de dirección este-oeste.

En la intervención de 2004 en la plaza Forqué (la más oriental), tenemos otro ejemplo, igualmente en las casas situadas al noreste del solar excavado y

patrilineal agnaticia, colateralidad, sexo y número de mujeres e hijo/as, bajo el principio de que cada uno de los hijos y mujeres, tíos y sobrinos debían percibir una parte proporcional de la herencia» (García-Bellido y García de Diego, 2000: 258).

15 La esquematización de las planimetrías de las excavaciones en el antiguo cuartel Sangenis, la de calle Murillo y otras anteriores ha sido elaboración mía; he tenido que realizar su inserción cotejando visualmente sus límites con los del parcelario actual, ya que no están depositadas en la administración autonómica la Memorias finales y los archivos informáticos que facilitarían la exactitud de ese encaje, ahora tan sólo aproximado. Agradezco a Víctor Esteban Martín, de APC S. L., la cesión de los archivos topográficos de la intervención de 2004 en la Plaza Forqué. 
del mismo modo dividiendo en dos la primitiva vivienda mediante un medianil norte-sur. El aspecto de los espacios residenciales de aparente disposición en espejo, no deja de ser la consecuencia de la inicial disposición en torno al patio de la casa islámica, dando una errónea impresión de una simetría intencionada. En este caso, la continuidad del muro llevó a sus excavadores a considerarlas correctamente como dos viviendas distintas en el estadio final de su evolución (Casas 2 y 3 ).

Se ha supuesto como explicación para el auge edilicio en esta zona y la mejor calidad de las construcciones de la plaza Forqué respecto a otros restos como los del paseo de la Independencia, la atracción que sentirían las élites locales hacia esa zona cercana a la residencia real de la Aljafería. Algo similar sucede en el arrabal cordobés de Cercadilla en torno a segundas residencias de la élite dominante, y que supondría el alejamiento de la medina como lugar de residencia de los estamentos más privilegiados de la sociedad. Parece existir una relación proporcional entre el cuidado y ornamento manifiesto en el uso de distintos pavimentos y el tamaño de las viviendas, lo que pudiera relacionarse, a su vez, con el estatus del propietario de la vivienda; así como una preocupación por adecuar el pavimento al uso de cada estancia (Camacho, 2008: 226).

Desconocemos la continuidad o separación existente entre las distintas zonas excavadas al sur de la madina; si pertenecían a un mismo arrabal o a realidades urbanas diferenciadas. Las fuentes andalusíes no permiten saber si los barrios tenían límites materiales visibles. La topografía de esta zona sugiere que la rambla que discurría desde Santa Engracia, por las actuales calles Casa Jiménez y Azoque pudo marcar una cesura a partir de la cual quizá se organizaran arrabales diferentes (Canellas, 1960: 208). Aún en el siglo XVIII de la huerta de Santa Engracia partía una senda que enlazaba con la prolongación del Azoque. ${ }^{16}$ Desconocemos si hubo canalizaciones de agua potable que abastecieran la madina, aunque no es difícil imaginar alguna derivación desde el río Huerva para los arrabales meridionales, sin que tengamos ninguna noticia de ello por el momento salvo la constatación de la existencia de acequias ya en época moderna por las calles antes mencionadas (Blasco, 1977: 17) y la noticia de que cerca de la puerta Cineja el llamado «Huerto del Rey» era muy apreciado por tener riego propio. (Beltrán, Lacarra, Canellas, 1976: 229).

16 En Málaga se ha comprobado que las vaguadas naturales, convertidas progresivamente en vertederos, permanecieron como zonas libres hasta la densificación de la ciudad en el siglo XI (Navarro, Jiménez, 2003: 359). 
Por otra parte, algún suelo de las viviendas halladas en el Teatro Fleta es un pavimento de mortero de calidad notable. Su ubicación lejos de la Aljafería considero que elimina ese argumento para interpretar una mejor calidad constructiva. Quizá debamos buscarla en una distinta procedencia de sus habitantes, con diferentes tradiciones edilicias o en una capacidad económica mejor, explicaciones que se emplean habitualmente en la historiografía. A esto habría que añadir la consideración de cómo debió expandirse y evolucionar la ocupación del entorno meridional de Saraqusța. Si como se cree - y la arqueología va constatando-, los arrabales crecían desde polos de atracción como puertas, mezquitas, baños, fuentes y calles principales, cabe preguntarnos qué elementos pudo haber en esta zona que propiciara una pronta edificación. En el área situada entre las puertas sur y oeste de la madina, la Aljafería y la iglesia de las Santas Masas, es precisamente el área del Teatro Fleta una de las más alejadas. Quizá eso contribuyó a una edificación posterior a la del resto de zonas documentadas. Los materiales cerámicos hallados en los niveles de construcción del arrabal no han proporcionado materiales califales sino de época taifa. Por ello me inclino a pensar que la implantación residencial en el entorno del Teatro Fleta pudo ser más tardía que en el paseo de la Independencia o en el entorno de la Plaza Forqué. Por otra parte, algunas estancias proporcionan algún material cerámico del siglo XIII que muestra una perduración de alguna vivienda en esa época, tal vez iniciando el proceso de la «morería cerrada» (Gutiérrez González, 2009: 299-302).

La reducción de las calles es otra respuesta lógica de la comunidad de vecinos a las necesidades de espacio en cada momento. En la ciudad islámica medieval la calle se modifica, incluso se elimina, especialmente cuando la urbe se encuentra en un periodo formativo. Se ocupan las calles sobre todo en la zona inmediata a la puerta de entrada de la vivienda ( $f i n \bar{a}$ '), algo permitido habitualmente por la justicia. Las autoridades judiciales sólo intervienen cuando hay conflicto entre vecinos. La permisiva jurisprudencia malikí sólo actuaba si la invasión de la calle reducía su anchura por debajo de lo estrictamente necesario. Si, como era mucho más frecuente, se aceptaba el hecho consumado, al cabo del tiempo el suelo quedaba incorporado por usucapión al patrimonio del infractor (Betrán, 2005-b: 79; Van Staëvel, 1995: 57). En el paseo de la Independencia tenemos ejemplos de esa invasión de la calle en las Casas 14 y 23 , así como algunos pilares de cantos adosados a muros exteriores de viviendas, inicio de posibles construcciones voladas. Si estimamos en torno a un siglo la vigencia de estas casas en cada fase (la taifa y en el siglo XII tras la 
Algunos contextos arqueológicos urbanos de Saraqusța

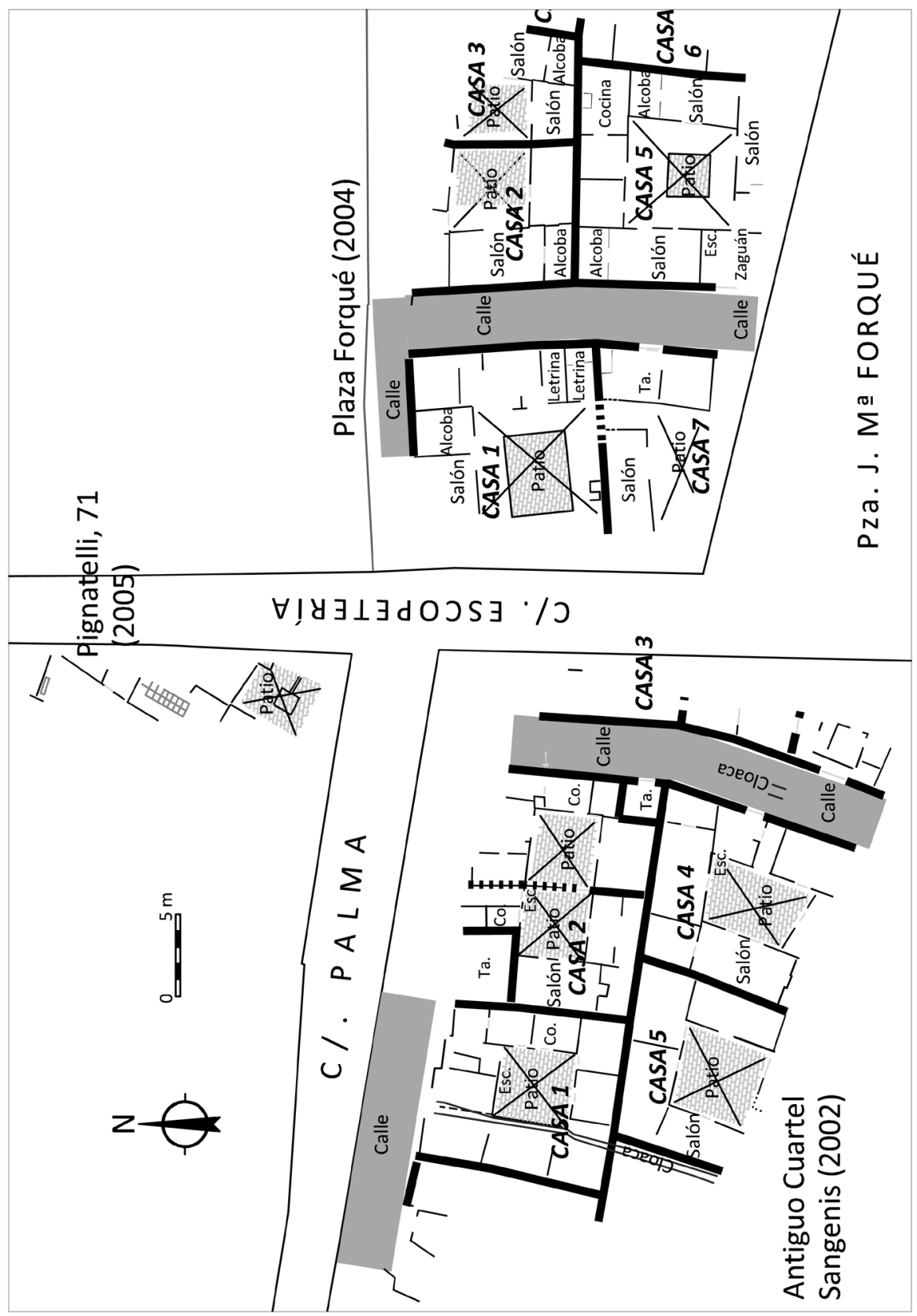

Figura 3. Planta de las viviendas del entorno de la Plaza J. Ma Forqué (elaboración propia) 
conquista), podemos imaginar como se hubiera desarrollado esa invasión de los viales con varios siglos más de vida de arrabal islámico (Gutiérrez González, 2006: 94-98, 117, 123 y133).

En la mayoría de ciudades de al-Andalus se desarrollarán numerosos arrabales, mientras que en Zaragoza se abandonan pronto por la conquista cristiana. El crecimiento en altura, con el auge de los pórticos-galería en planta, tiene lugar en al-Andalus desde mediados del XII, por eso no hay ejemplos de estas construcciones en Zaragoza. Aquí las escaleras son seguramente hacia una simple algorfa. Si se produce la invasión aérea del espacio es porque en superficie previamente ya se había ocupado todo lo apropiable. El proceso de crecimiento en altura en la Zaragoza taifa ya habría comenzado, pero es poco probable que hallemos algún ejemplo de pórtico-galería. Debido a la necesidad de no violar la intimidad del vecino es muy difícil encontrar diferentes alturas dentro de un mismo barrio (Youssef Hoteit, 1993: 29). El ancho de los muros no nos proporciona información sobre la altura pues la anchura media de las estructuras oscila siempre en torno a los 0,50/0,55 m, no apreciando ninguna diferencia entre aquellas estructuras que parecen corresponder a los limites exteriores de las manzanas o las que constituyen la subdivisión interior de las diversas estancias, salvo los tabiques que generan algún pequeño espacio.

\section{Procesos de desbordamiento}

Lo más habitual fue la cerca incluyese todo y no dejase nada extramuros. Tras la expulsión fuera de la madina de las actividades artesanales, también comienzan las residenciales formando arrabales. El incremento de población precisó de un ensanche residencial que atestiguamos en esta zona al Sur de Saraqusta. Al contrario que en el interior de la madina - dónde se produce una singular reutilización de estructuras urbanas preislámicas (Almagro, 1987) - , el arrabal se crea con una planificación que requiere capacidad de organización y trabajo, como la nivelación del terreno previo, tal vez impulsado desde el gobierno de la taifa. La planificación se centraría en las calles principales, las que separan barrios, mientras que las manzanas y calles menores son producto de las decisiones del grupo asentado. En el paseo de la Independencia, al igual que en Pechina (Almería) y otros lugares del Norte de África, un adarve se inserta en la trama urbana ya en la planificación original, posiblemente requerido por la necesidad inicial de espacio que supuso una masiva inmigración a primeros del siglo XI. 


\section{El viario}

El viario está estrechamente ligado a la propiedad privada de la casa. Se aprecia una jerarquización de las calles, resultante de la relación con la casa, con el espacio privado. Las reformas se hacen con el acuerdo unánime de los vecinos asociados en el espacio inmediato a la casa (finā') y en el adarve o espacio de circulación sin salida de propiedad semiprivada en copropiedad entre los vecinos. Así, la calle muestra una gradación desde las vías principales, las calles de barrio, las calles menores y los adarves. Una cita del profeta establece el mínimo de anchura en siete codos.

Antes mencionaba el interés de las autoridades locales tardoantiguas por mantener los derechos de la vía pública. Sin embargo, en la ciudad islámica no hay autoridad local como tal, sino que el gobernante es elegido directamente por el emir o califa. Aunque los juristas malikís eran unánimes en proteger la vía pública de las violaciones de los vecinos, tenían diferencias si la usurpación no era dañina. Aunque la opinión dominante fue no admitir ninguna trasgresión en detrimento del dominio público, cualquiera que sea la anchura y aunque no moleste a los usuarios, los doctores en derecho musulmán pusieron una corrección importante: la sumisión ante los hechos consumados durante un largo tiempo (usucapión). Si la ocupación de la vía pública es muy antigua y no ha suscitado ninguna reclamación, puede ser tolerada. Esta máxima repetida durante siglos llevó a la ciudad islámica a su aspecto tradicional, aún desde un posible origen regular y holgado.

Otro punto vertebrador de la traza urbana fue la consolidación de los caminos preexistentes. Esos caminos pueden ser las líneas de división entre parcelas agrícolas preexistentes. Una de las características de los caminos agrícolas son las bifurcaciones practicadas según las necesidades topográficas, pero en Zaragoza no he apreciado ninguna que pudiera haber quedado fosilizada en el parcelario, salvo quizás en la calle Agustina de Aragón con R. Pignatelli.

El trazado de los viales conocidos se aproxima bastante a una retícula, con desviaciones escasas debidas a una ligera adaptación a la topografía previa. La Calle principal bajo el paseo de la Independencia presenta un suave giro que pudo estar condicionado por la existencia de alguna construcción previa, quizás la mezquita de Abū Jālid, citada en las fuentes junto a la puerta Cinejia (Corral, 1998: 55 y 60) ${ }^{17}$ Este desarrollo pudo estar condicionado por el terre-

17 También pudo deberse a que «en la calle musulmana, aunque se trate de una arteria de tráfico, esta continuidad se rompe siempre con un recodo o con un quiebro que rompe la perspectiva» (Youssef 
no que encontraron los musulmanes al plantear el arrabal sobre la terraza del Huerva y las posibles modificaciones del terreno desde época romana. Queda pendiente dilucidar si el trazado de las calles del arrabal taifa fue producto de la adaptación a los caminos agrícolas de las fases precedentes.

Esa calle principal bajo el paseo de la Independencia se va cerrando desde los 4 metros de anchura al Norte, hasta alcanzar sólo 3 metros al perderse en el talud de la excavación. De las calles transversales la más cercana a la medina tiene 3 metros de ancho; mientras que las dos siguientes llegan a los 2,5 m. El adarve de la Manzana 1 tiene 1,8 m. Hemos podido comprobar en los límites de la excavación que las calles de eje E-O continúan, junto a nuevas manzanas hacia el Este. El resto de calles documentadas en otros solares tienen similares características físicas con suelos de gravas compactadas, salvo el adarve localizado en la calle Murillo (antiguo cine Dorado), que según sus excavadores «presenta un firme de tierra batida» de difícil comprensión. Además de la fundamental diferencia en sus infraestructuras sanitarias de evacuación de aguas antes comentado y que corresponden a iniciativas de grupos de particulares (Rèklaityte, 2012; Vidal, 1999).

\section{Manzanas}

La «hegemonía de lo privado» configura también la estructura interna del arrabal. La idea del mundo del hombre musulmán condiciona la estructura de su vivienda y la inserción de ésta dentro del conjunto vecinal que crea la ciudad. En lo económico se manifiesta en la especial presencia del zoco; en la implantación en el urbanismo del modo de producción de pequeño mercado simple, en su doble faceta de comercio y artesanía (Acién, 2001: 30-32). En la Manzana 1 del paseo de la Independencia la inserción de talleres y tiendas se realiza llevándolas a la periferia de la manzana para facilitar la interacción con los viandantes; mientras que se les dota de una superficie notablemente inferior a la de las viviendas y una estructura simple de una estancia o dos a lo máximo, añadiendo otra al fondo que funcionaría como almacén. En las nuevas intervenciones ahora comentadas también podemos intuir otras como la citada más arriba o el espacio situado en la esquina sureste de la casa 2 del antiguo cuartel Sangenis [Figura 3.2002]. En el nivel de estudio de materiales que he podido alcanzar, resulta imposible atribuir alguna función artesanal o

Hoteit, 1993: 35). Sin embargo esta visión parece justificar un hecho consumado y no tener en cuenta el proceso de evolución de la ciudad islámica. 
comercial concreta a estas tiendas. En todo caso, el hallazgo de coladas de fundición de hierro, en alguna estancia de esa Manzana 1, podría interpretarse como la tendencia de los productores a mantener la máxima cercanía a los espacios de venta, antes que primar la facilidad de mayor espacio en otras zonas, la menor carestía del suelo en áreas más alejadas o evitar los elementos contaminantes; en línea de la citada propuesta de «mercado simple».

La fortuna quiso que el límite predefinido de excavación en el paseo de la Independencia haya permitido constatar al menos el inicio de varias manzanas, lo que permite realizar un estudio más completo de los módulos de asentamiento. Aproximadamente, la Manzana 1 tiene 33 por $36 \mathrm{~m}(1.170 \mathrm{~m} 2)$ y para la Manzana 2 suponemos unos 27 por $29 \mathrm{~m}(783 \mathrm{~m} 2)$, siendo esta última aproximadamente $2 / 3$ de la primera, sobre todo si contamos con los viales (Gutiérrez González, 2006: 55-56). Es decir, el adarve trazado en el momento crear la Manzana 1, añade un tercio más de superficie a la Manzana 1 respecto a la Manzana 2. Sin embargo, los demás restos documentados no permiten conocer sus dimensiones, teniendo que suponer demasiados datos para llegar a conclusiones seguras. Sólo puede asegurarse que en la plaza Forqué la manzana central existente, entre los dos solares excavados en 2002 y 2004, tendría unos $22 \mathrm{~m}$ de lado; pudiendo tener mayores dimensiones las otras dos parcialmente descubiertas.

\section{Viviendas}

Para Julio Navarro (conferencia impartida el 23 de enero de 2014 en la Casa Árabe de Córdoba), los espacios públicos no son los primeros en diseñarse en las ciudades de al-Andalus, lo habitual es que el viario sea resultado de la ordenación previa de los espacios privados. Por ello su análisis es imprescindible para el estudio del urbanismo histórico. «Sólo comprendiendo correctamente los procesos evolutivos de la vivienda podemos acceder al desarrollo del parcelario de las ciudades andalusíes.»

Así pues, el estudio del microespacio es imprescindible para entender la ciudad islámica a nivel urbanístico. En lo constructivo, la hegemonía de lo privado se plasma en «el estricto respeto de las servidumbres de vista, de manera que se garantice la intimidad de la casa», que se entremezcla con lo económico en la máxima adyacencia entre las propiedades por la servidumbres de muros medianeros. Ya en la tardoantigüedad se impuso el pragmatismo también en el ambiente doméstico, el cual se combina con los espacios destinados 

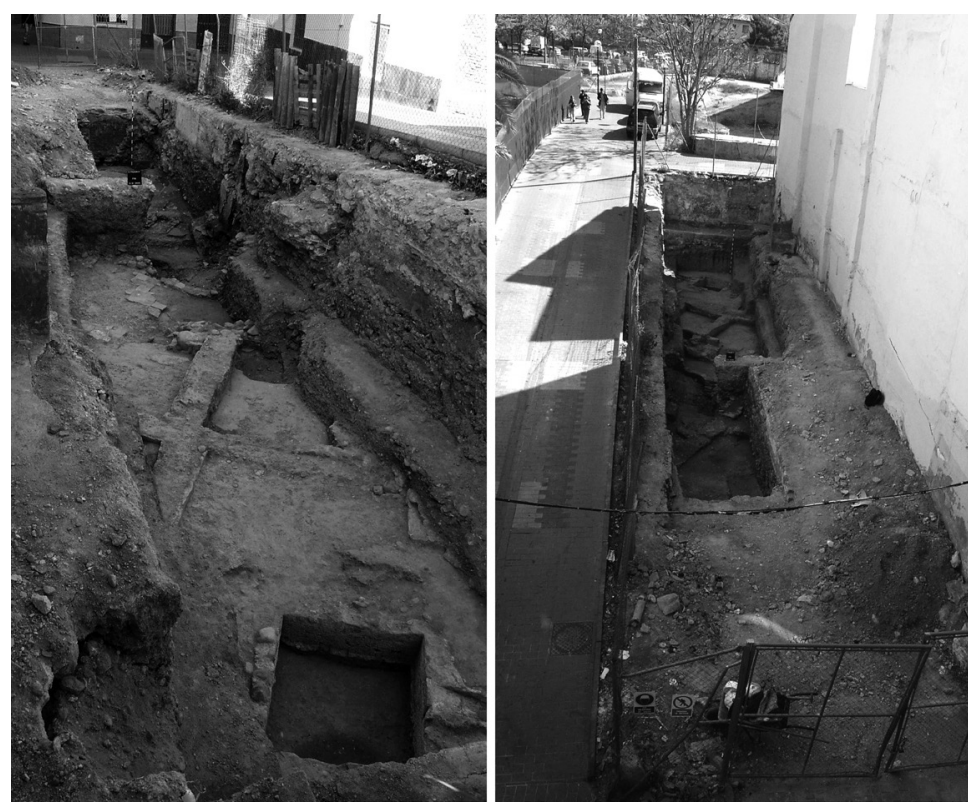

Figura 4. Vistas desde el norte y el sur de la viviendas halladas en la Calle R. Pignatelli, 71

a funciones artesanales e incluso comerciales. Es decir, no es algo propio del urbanismo islámico, sino continuidad del precedente.

Un ejemplo de adaptación privada, en este caso a un desnivel topográfico abrupto, lo tenemos en la estancias excavadas en el número 71 de la calle $\mathrm{R}$. Pignatelli (lateral a calle Escopetería), adyacentes a los amplios restos de las dos intervenciones de la Plaza Forqué, pero a una cota inferior en unos dos metros de altura (derivado de una terraza del Ebro). Las cotas de los restos de la calle Pignatelli oscilan entre 201,5 y 202 m snm, mientras que los de plaza Forqué (2004) oscilan alrededor de entre 203 y 204 m snm. Las alineaciones de estas viviendas giran hasta 36 grados respecto de las anteriores, aunque la conexión concreta ha quedado oculta bajo las vías peatonales que separan estos solares [Figuras 3 y 4]. El pequeño solar excavado en el $n^{\circ} 71$ de la calle Pignatelli tiene la geometría de rectángulo alargado típico de la ordenación del reparto feudal, expansión que ya no llegó más al sur en esta zona (Torró, 1993: 536-537; Navarro, Jiménez, 2001: 108-124). El modelo doméstico de casa organizada en torno a un patio central cuadrado o rectangular es un factor principal que contribuye a dotar a la ciudad islámica de una personalidad diferente de la ciudad del occidente cristiano. Mientras la vivienda cristiana 
puede prescindir del patio, formando fincas estrechísimas abiertas a la calle; la islámica está obligada a mantenerlo, aunque sus dimensiones sean mínimas, generándose así parcelas cuadradas o rectangulares que pueden estar en el interior de grandes manzanas (Navarro, Jiménez, 2003: 337 y 362 nota 191).

\section{Perduración del urbanismo islámico}

En el arrabal del Paseo de la Independencia se ha documentado una única reforma generalizada de todos los espacios, que puede relacionarse con el momento de la conquista aragonesa de la ciudad. El final de la ocupación de este arrabal estaría en relación con el inicio de construcción de las cimentaciones absidiadas de una iglesia proyectada a principios del siglo XIII y que nunca llegó a construirse (Gutiérrez González, 2006: 40-51). No podemos saber con seguridad si esta reforma se dio en toda la ciudad o si sólo afectó determinados sectores. Sabemos que el entorno de la plaza Forqué queda abandonado sobre el 1.118 y durante varios siglos. La diferencia con la zona del paseo de la Independencia podemos buscarla en la centralidad comercial de la vía hacia las Santas Masas y la pérdida de influencia de la Aljafería tras la conquista feudal. Esta reforma generalizada del arrabal del paseo de la Independencia a comienzos del siglo XII - que también se constata en el solar de la calle Murillo-, debe enmarcarse dentro de la salida forzosa de los musulmanes desde la medina hacia el exterior, configurándose un barrio específico que, aunque reproduce los modelos de vivienda tradicionales, presenta algunos elementos de difícil interpretación; y que en el plano urbanístico se adapta a los viales existentes, transformando parcialmente las manzanas. Debido a una menor densidad de población respecto al siglo precedente, la necesidad de espacio se reduce y los ámbitos agropecuarios pudieron integrarse entre las viviendas, como parece deducirse del espacio abierto que se configura en el interior la Manzana 1. A lo largo de su discurrir histórico, no se produce aquí la teórica y clásica idea de la conversión de una calle principal en zoco, probablemente por la regresión de la ciudad en los siglos XII y XIII - y de la población musulmana en especial - , que la dejaría fuera de la principal área comercial. Estas estructuras nos han llegado con un mayor índice de arrasamiento que las precedentes, por lo que no podemos precisar en todos los casos detalles de las fórmulas de habitación. Sí se aprecia una perduración de la ocupación conforme nos acercamos a la puerta de la ciudad, pues en la calle 7 los pozos ciegos proporcionaron algún fragmento de cerámica del siglo XIV, 
lo que no sucede en ningún otro lugar de toda la excavación en el paseo de la Independencia. Mientras, en el más alejado Teatro Fleta las estancias quedan abandonadas a fines del siglo XII o inicios del XIII y no se reutilizan, quedando la zona para funciones artesanales a partir de mediados del siglo XIV (Gutiérrez González, 2009: 283-284). Los aún más lejanos inmuebles de Plaza Forqué no verán alterados sus restos por nuevas construcciones incluso hasta época contemporánea.

Se ha venido repitiendo que el trazado urbano islámico ha perdurado mucho en ciudades como Murcia, Mallorca y otras, por lo que se ha venido rastreando sus huellas en los parcelarios de catastros y planos de época moderna (Jiménez, Navarro 2000, 2001, 2007 y 2009-b; Roselló Bordoy 2006; Tahiri 1998; Pinon, 1998). Lo cierto es que para Zaragoza, aunque está pendiente un trabajo en profundidad que combine la documentación topográfica, cartográfica y catastral; los escasos restos arqueológicos conservados al interior de la madina harán difícil que esta metodología sea productiva. Algunos autores han propuesto diversas metodologías de investigación (Salvatierra, García, 2001). Para Zaragoza son indispensables los trabajos de Falcón y Ledesma y algunos artículos puntuales. Una línea de investigación importante ha propuesto el estudio de las mezquitas de barrio que perviven y se transforman en iglesias cristianas tras la conquista; para lo cual debe integrarse como elemento prioritario la implementación de la arqueología de la arquitectura en la rehabilitación de edificios históricos y otras reformas urbanísticas (Epalza, 1995; Buresi, 2000; Jiménez y Navarro, 2001: 111-124; Rütenik, 2009; González Gutiérrez, 2012).

Chueca-Goitia propuso que la estructura de la «ciudad convento» cristiana es el resultado directo de la ciudad islámica, pues la fundación de los conventos en época Moderna no lleva aparejada la creación de edificios de nueva planta, sino que se acotan por medio de tapiales sectores de la anterior ciudad islámica y dentro de estos muros quedan - inmovilizados y cerrados - , edificios, callejones y pasadizos. Una revisión pormenorizada de la cartografía y la configuración de esos conventos, tan numerosos en Zaragoza, con suerte quizá podría sugerir puntos concretos del recorrido del muro de «rejola» medieval.

Por otra parte, al interior del muro de piedra, se debió combinar la reutilización de estructuras con modificaciones necesarias para las funciones requeridas por la nueva sociedad que las ocupó. En un primer momento, perduraron las tiendas en torno a la mezquita, ahora convertida en templo cristiano. Prueba de ello parecen ser los pozos hallados en la excavación de la catedral de la 
Seo, en la que de los diecinueve pozos sépticos andalusíes, pasamos a contabilizar hasta veintiséis pozos de cronología bajomedieval.

La correcta comprensión de los restos arqueológicos será imprescindible para ir más allá del urbanismo y poder hacer historia de la producción e historia social, tal y como intentan las últimas investigaciones (García Porras, 2013); y de ese modo llegar a la lectura de «la dimensión semiótica, que las analiza como expresiones sociales, materialización e instrumento de significados culturales, y se centra en el uso social del entorno construido, es decir, en las relaciones entre los espacios construidos y la estructura social que los concibe y ejecuta a través de expresiones arquitectónicas concretas» (Gutiérrez Lloret, 2012: 140).

Muchas evidencias importantes quedan en los informes de excavaciones archivados y no publicados, algunas desconocidas y otras que no he podido integrar en este artículo debido a su gran carga de trabajo. Espero que estas páginas puedan servir para despertar el interés de algún investigador que renueve los estudios históricos y arqueológicos del mundo andalusí en Zaragoza y Aragón.

\section{Referencias bibliográficas}

ACIÉN, M. (2001), «La formación del tejido urbano en al-Andalus», en La ciudad medieval: de la casa al tejido urbano, J. Passini (Ed.), Actas del Ier Curso de Historia y Urbanismo Medieval, 11-32.

ACIÉN, M., VALLEJO, A. (1998), «Urbanismo y Estado islámico: de Corduba a Qurtuba - Madînat al-Zaharâ» en Cressier, P.; García-Arenal, A. (Ed.), Genèse de la ville islamique dans l'Andalus et au Maghreb Occidentale, 107-136.

ALBA, M. (2004), «Apuntes sobre el urbanismo y la vivienda de la ciudad islámica de Mérida», Memoria 7, Consorcio de Mérida, 417-438.

ALMAGRO, A. (1987), «Planimetría de las ciudades hispanomusulmanas», Al-Qantara VIII, 421-448.

AGUAROD, M. ${ }^{a}$ C., ESCUDERO, F. de A. (1991), «La industria alfarera del barrio de San Pablo» en AA.VV., Zaragoza. Prehistoria y arqueología, Zaragoza, Gerencia de urbanismo. Ayuntamiento de Zaragoza, 44.

AGUAROD, M. ${ }^{a}$ C., MOSTALAC, A. (1998), La arqueología de Zaragoza en la Antigüedad tardía, Historia de Zaragoza 4, Ayuntamiento de Zaragoza - CAI.

ÁlVAREZ, A., MOSTALAC, A., AGUAROD, M ${ }^{\mathrm{a}}$. C., GALVE, M. ${ }^{\mathrm{a}}$ P., ESCUDERO, F. (1986), Arqueología urbana en Zaragoza (1984-1986), Zaragoza, Excmo. Ayuntamiento de Zaragoza, Gerencia Municipal de Urbanismo y Diputación General de Aragón, Departamento de Cultura y Deporte. 
AZUAR, R. (2008), «Formación de la ciudad islámica en el Sharq Al-Ándalus (Siglos IX-X/III-IV)», en Izquierdo, R.; Carrobles, J. (eds.) Al-Andalus, país de ciudades. Actas del Congreso celebrado en Oropesa (Toledo), del 12 al 14 de marzo de 2005, 79-105.

BETRÁN, R. (1996), «Mutación y permanencia: el plano de Zaragoza en la Edad Media», XXII Semana de estudios medievales, Estella 17-21 de junio de 1995, Gobierno de Navarra, Pamplona, 381-433.

- (2005), «Continuidad, proyecto y evolución urbana en Saraqusta (714-1118)», en Zaragoza, espacio histórico, Centro de Historia de Zaragoza, 35-73.

- (2005- $b)$, «Planeamiento y geometría en la ciudad medieval aragonesa», Arqueología y Territorio Medieval 12.2, Jaén, 75-146.

BELTRÁN, A.; Lacarra, J. M.; Canellas, A. (1976), Historia de Zaragoza, I, Edades Antigua y Media, Ayuntamiento de Zaragoza.

BLANCO, R. (2014), «Hacia Una ciudad en transición: el inicio de la Córdoba Islámica», en D. Vaquerizo, Garriguet, J A., León, A., (Eds) Ciudad y Territorio: transformaciones materiales e ideológicas entre la época clásica y el Altomedievo, Córdoba, Monografías de Arqueología Cordobesa 20, 185-199.

BLASCO, R- M. (1977), Zaragoza en el siglo XVIII (1700-1770), Colección «Aragón».

BURESI, P. (2000), «Les conversions d'églises et de mosquées en Espagne aux XIeXIIIe siècles», en Religion et société urbaine au Moyen Âge. Mélanges offertes à Jean-Louis Biget par ses anciennes élèves, Pub. De la Sorbonne, Paris, 333-350.

CAMACHO, C. (2008), «Estudio sobre pavimentación en la vivienda del siglo X», Arte, Arqueología e Historia, 15, 221-235.

CANELLAS, A. (1960), «Evolución urbana de Zaragoza», en Estudios de urbanismo, Institución Fernando El Católico - Colegio Oficial de Arquitectos de Aragón y Rioja, 207-228.

CASAL, M. ${ }^{\text {a }}$ T. (2008), «Características generales del urbanismo cordobés de la primera etapa emiral: el arrabal de Saqunda», Anejos de Anales de Arqueología Cordobesa, 1, Córdoba, 109-134.

CORRAL, J. L. (1987), «El sistema urbano en la Marca Superior de al-Andalus», Turiaso, VII, 25-64.

- (1991), «Las ciudades islámicas en Aragón», Simposio internacional sobre la ciudad islámica: ponencias y comunicaciones, Zaragoza, IFC, 253-287.

- (1998), Zaragoza musulmana (714-1118), Historia de Zaragoza 5, Ayuntamiento de Zaragoza - CAI.

- (2008), «El diseño urbano de la Zaragoza islámica», Revista del Instituto Egipcio de Estudios Islámicos, Vol. XXXVI Zaragoza, Madrid, 191-240.

CRESSIER, P.; FIERRO, M.; VAN STAËVEL, J. P. (2001), (Eds.) L'urbanisme dans l'Occident musulmane au Moyen Âge, aspects juridiques, Casa de Velázquez, CSIC, Madrid. 
DIARTE, P. (2012), La configuración urbana de la Hispania tardoantigua. Transformaciones y pervivencias de los espacios públicos romanos (s. III-VI d.C.), BAR Internacional Series, 2429, Oxford.

EPALZA, M. de, (1985), «Un “modelo operativo” de urbanismo musulmán», Sharq al-Andalus 2, 137-149.

- (1995), «Mutaciones urbanísticas debidas a la transformación de mezquitas en iglesias» en VI Simposio internacional de Mudejarismo, Teruel, 16-18 de septiembre de 1993, Actas, 501-518.

EPALZA, M. de; CORRAL, J. L. (1991), (Eds.) Simposio internacional sobre La ciudad islámica: ponencias y comunicaciones, Zaragoza, IFC.

ESCUDERO, F. de A., Galve M. a P, «Caesaraugusta», en Remolá, J.A., Avero, J. (eds.) La gestión de los residuos urbanos en Hispania, Anejos del Archivo Español de Arqueología, LX, -280.

FALCÓN, M. a I. (1981), Zaragoza en el siglo XV, Morfología urbana, huertos y término municipal, IFC y Ayuntamiento de Zaragoza.

FATÁS, G. (1977), «Para una bibliografía de las murallas y puente de piedras de Zaragoza, según las fuentes escritas hasta 1285», Estudios Medievales, Homenaje a Lacarra, Vol. II, Zaragoza, 305-328.

GALVE, M. ${ }^{\text {a }}$ P. (1989), «Arqueología en Zaragoza: informe preliminar de la excavación de la calle Espoz y mina, $\mathrm{n}^{\circ}$ 8-10», Crónica del XIX Congreso Arqueológico Nacional, Vol. 2, Zaragoza, 409-420.

- (1990), «Arqueología medieval en Zaragoza», Estado actual de la arqueología en Aragón, Vol. 2, (Comunicaciones), Zaragoza, 321-332.

- (1991), «Nuevas aportaciones de la Arqueología a la ciudad islámica de Zaragoza», Simposio internacional sobre la ciudad islámica: ponencias y comunicaciones, Zaragoza, IFC, 377-384.

- (1991), «Las necrópolis islámicas de Zaragoza. La necrópolis de la Puerta de Toledo» en Zaragoza. Prehistoria y Arqueología, Ayuntamiento de Zaragoza, 45-46.

- (1995), «Necrópolis islámica de la Puerta de Toledo (Zaragoza): nuevas excavaciones», en M. P. Acién y M. ${ }^{\circ}$ P. Torres (coord.) Estudios sobre cementerios islámicos andalusíes, 117-136.

- (2009), «El espacio urbano en la Zaragoza islámica: balance y algunas novedades», Primeras Jornadas de Arqueología Medieval en Aragón, Teruel 15-17 de junio de 2006, Teruel, 157-204.

- (2014), «Zaragoza antigua: Salduie, y Caesaraugusta): actualidad de la investigación arqueológica», en Martín-Bueno, A., Sáenz, J. C. (Eds.) Modelos edilicios y prototipos en la monumentalización de las ciudades de Hispania, Monografías Arqueológicas 49, PUZ, 43-55.

GALVE, M. ${ }^{a}$ P. y BENAVENTE, J. A. (1991), «Las necrópolis islámicas de Zaragoza» en Zaragoza. Prehistoria y Arqueología, Ayuntamiento de Zaragoza, $85-98$. 
GALVE, M. ${ }^{\text {a }}$ P. y BENAVENTE, J. A. (1992), «La necrópolis islámica de la Puerta de Toledo de Zaragoza», en III Congreso de Arqueología Medieval Española, Oviedo 1989, Actas, Vol. 2, Comunicaciones, 383-390.

GARCÍA TERREL, A. Ma (1999), El barrio y la parroquia de Santa Engracia de Zaragoza entre 1600 y 1900, Colección Estudios y Monografías 29, Gobierno de Aragón, Zaragoza.

GARCÍA-BELLIDO y GARCÍA DE DIEGO, J. (1998), «Principios y reglas morfogenéticas de la ciudad islámica», Qurtuba 2, 59-86.

- (2000), «Morfogénesis de la ciudad islámica: algunas cuestiones abiertas y ciertas propuestas explicativas», en P. Cressier, M. Fierro, J.-P. Van Saëvel, Urbanisme musulman, Casa de Velázquez-CSIC, 243-283.

GARCÍA BIOSCA, J.E., GIRALT, J., LORIENTE, A., MARTÍNEZ, J. (1998), «La génesis de los espacios urbanos andalusíes (siglos VIII-X): Tortosa, Lleida y Balaguer)» en García Biosca, J.E. y Giralt, J. (eds.) El Islam y Cataluña, Institut Català de la Mediterrània-Museu d’Història de Catalunya-Lunwerg Editores, 137-165.

GARCÍA PORRAS, A. (2013), «Arqueología medieval, historia de la Cultura Material y Arqueología de la Producción. Reflexiones sobre su origen e inicios de un debate sobre su futuro» en García Porras, A. (ed.), Arqueología de la producción en época medieval, Alhulía, S.L., Granada, 11-38.

GIRALT, J., Tuset, F. (1994), «Modelos de transformación del mundo urbano en el nordeste peninsular. Siglos V-XI», IV Congreso de Arqueología Medieval Española, vol. I Ponencias, 37-46.

GISBERT, J. (1993), «Dāniya y la Vila de Denia. En torno al urbanismo de una ciudad medieval», en Azuar; R. Gutiérrez, s.; VALDÉS, R., Urbanismo medieval del País Valenciano, Biblioteca de Arqueología Medieval Hispánica, Madrid, 63-103.

GRANJA, F. de la, (1967 ), «La Marca Superior en la obra de al-'Udīì, Estudios de la Edad Media de la Corona de Aragón, VIII, 447-545.

GUICHARD, P. (1977), Structures sociales, orientales et occidentales dans l'Espagne musulmane, Mouton, Paris-La Haye.

- (1998), «Les villes d'al-Andalus et de l'Occident musulmane aux premiers siècles de leur historie. Une hypothèse récente», en Cressier, P.; Garcia-Arenal, A. (Ed.), Genèse de la ville islamique dans l'Andalus et au Maghreb Occidentale, 37-52.

GUICHARD, P., VAN STAËVEL, J. P., «La casa andalusí: ensayo de lectura antropológica», en Casas y palacios de al-Andalus. Siglos XII y XIII, J. Navarro (Ed.), El legado andalusí - Lunwerg Editores S.A., 45-51.

GONZÁLEZ GUTIÉRREZ, M. C. (2012), Las mezquitas de barrio de Madinat Qurtuba: una aproximación arqueológica, Diputación de Córdoba, Córdoba.

- (2014), «Hacia la ciudad islámica: de la percepción tradicional a la conceptualización arqueológica» en D. Vaquerizo, Garriguet, J A., León, A. (), (Eds) Ciudad y Territorio: transformaciones materiales e ideológicas entre la época clásica y el Altomedievo, Córdoba, Monografías de Arqueología Cordobesa 20, 201-214. 
GUTIÉRREZ GONZÁLEZ, F. J. (2006), La excavación arqueológica del paseo de la Independencia de Zaragoza. Febrero - mayo de 2002, Madrid, GrupoEntorno.

- (2007), «La excavación arqueológica del n ${ }^{\circ} 8$ de la calle Cinco de Marzo (patio de la Diputación Provincial de Zaragoza. $1^{a}$ fase», Salduie 6, Revista del Departamento Ciencias de la Antigüedad de la Universidad de Zaragoza, Zaragoza, 351-387.

- (2009), «La excavación arqueológica del Gran Teatro Fleta de Zaragoza. Catas en 2001 y campañas 2002 y 2005», Salduie 7, Zaragoza, 281-308.

- (en prensa), «La muralla romana en el n $n^{\circ} 2-4$ de la calle Mártires de Zaragoza», Salduie 14.

- (en prensa-b), La cerámica andalusí de la Seo de Zaragoza, Col. «Varia», Departamento de Historia Medieval, Ciencias y Técnicas Historiográficas y Estudios Árabes e Islámicos de la Universidad de Zaragoza.

GUTIÉRREZ GONZÁLEZ, F. J.; De MIGUEL MILLÁN C. (2009), «La cerámica del arrabal meridional de Zaragoza en época medieval», Primeras Jornadas de Arqueología Medieval en Aragón, Teruel 15-17 de junio de 2006, Teruel, 427-459.

GUTIÉRREZ LLORET, S. (2012), «Gramática de la casa. Perspectivas de análisis arqueológico de los espacios domésticos medievales en la Península Ibérica (siglos VII-XIII)», Arqueología de la Arquitectura, 9, enero-diciembre 2012 Madrid/ Vitoria, 139-164.

HERNÁNDEZ VERA, J. A. (2004), «La mezquita aljama de Zaragoza a la luz de los hallazgos arqueológicos», ILU. Revista de Ciencias de las religiones, Anejos, X, 65-91.

JIMÉNEZ, P. (2002), «Algunas reflexiones en torno al urbanismo islámico de la Región de Murcia», en Iniesta, A., Jiménez, P., Martínez, J. A., Pozo, I. (coords.), Urbanismo islámico en el sur peninsular y norte de África, Murcia, 83-106.

JIMÉNEZ, P.; NAVARRO, J. (2000), «Génesis y evolución urbana de Murcia en la Edad Media» en Murcia, ayer y hoy, Colección Museo de la Ciudad, Murcia, 40130 .

- (2001), «El urbanismo islámico y su transformación después de la conquista cristiana: el caso de Murcia», La ciudad medieval: de la casa al tejido urbano, (J. PASSINI Coord.), Ier. Curso de Historia y Urbanismo Medieval, Cuenca, 71-129. KHIARA, Y. (1995), «Propos sur l'urbanisme dans la jurisprudence musulmane», Arqueologia Medieval 3, Mertola, 33-46.

LACARRA, J. M., «La conquista de Zaragoza por Alfonso I (18 de diciembre de 1118) », Al-Andalus, XII, Madrid, 65-96.

- (1950), «El desarrollo urbano de Navarra y Aragón en la Edad Media», Pirineos 15 y 16 , Zaragoza.

LAFUENTE, M. (en prensa), «Las murallas de Zaragoza en la Edad Media», en VII Jornadas de Castellología Aragonesa: Recintos amurallados, Asociación para la Recuperación de los Castillos en Aragón (ARCA), Zaragoza. 
LEDESMA, M. a L. (1967), La encomienda de Zaragoza de la orden de San Juan de Jerusalén en los siglos XII y XIII, Universidad de Zaragoza, Zaragoza.

- y FALCÓN, M. ${ }^{a}$ I. (1977), Zaragoza en la Baja Edad Media, Colección Aragón, 17, Librería General.

LORIENTE, A. (1990), L’horizont andalusí de l'antic Portal de Magdalena, Monografies d'arqueologia urbana 2, Lleida.

- y GIL, I.; PAYÀ, X. (1997), «Un exemple de model urbá andalusí: medina Larida. L'aportació de d'arqueologia urbana al món àrab», Revista d'Arqueologia de Ponent 7, 77-106.

LORIENTE, A.; OLIVER, A. (1992), (Ed.), L'antic Portal de Magdalena, Monografies d'arqueologia Urbana 4, Lleida.

MALPICA, A. (2007), «El modelo islámico de ciudad. Reflexiones sobre la madina andalusí», en Mercado inmobiliario y paisajes urbanos en el Occidente Europeo (siglo XI-XV), XXXIII Semana de Estudios Medievales (Estella, 2006), Pamplona, 567-589.

MARTÍN-BUENO, M. A. y SÁENZ PRECIADO, J. C. (2000), «El palacio de La Aljafería a través de sus intervenciones arqueológicas», Aragón en la Edad Media, $15,505-520$.

MAZZOLI-GUINTARD, Ch. (1998), «L'urbanisation d'al-Andalus au IXe siècle: données chronologiques», en Cressier, P., Garcia-Arenal, A. (Ed.), Genèse de la ville islamique dans l'Andalus et au Maghreb Occidentale, 99-106.

- (2000), Ciudades de al-Andalus. España y Portugal en la época musulmana (S. VIII-XV), ALMED, Granada.

- (2002), «Urbanisme islamique et ville en al-Andalus: autour de nouvelles propositions méthodologiques», Actas II Congreso Internacional La ciudad en al-Andalus y el Magreb (Algeciras, 26-28 de noviembre de 1999), Granada, 49-73.

- (2002-b), «Las ciudades islámicas: tipología y evolución en la península ibérica», Cuadernos de la Alhambra vol. 38, Granada, 49-83.

- (2004), «Des pouvoirs dans la ville d'al-Andalus: du pouvoir politique aux intentions citadines (IVe-Xe/Xe-XIe siècles) », Al-Andalus-Magreb, X, 129-151.

- (2011), «Los territorios urbanos de las ciudades andalusíes: perspectivas de estudio», en V. Martínez Enamorado (ed.) I Congreso Internacional Escenarios urbanos de al-Andalus y el Occidente musulmán. Vélez-Málaga 16-18 de junio de 2010, Málaga, Universidad de Nantes (Francia), 17-44.

- (2014), «Du puits au cadi. Gestion et conflits de l'alimentation en eau à Cordoue (VIIIe-XIIIe siècles)», Anaquel de estudios árabes, 25, 99-128.

MOLINA, A. L. (1992), Urbanismo medieval: la Región de Murcia, Universidad de Murcia.

MOSTALAC, A. (1990), «Los hornos islámicos de Zaragoza» en Fours de potiers et testares médiévaux en Méditerranée Occidentale, Madrid, Publications de la Casa de Velazquez, Serie Archéologie XII, 63-74. 
MOSTALAC, A., GALVE, M. P. (1986), «Informe preliminar de la excavación en la Pza. del Rosario de Zaragoza», Arqueología Aragonesa, 84, Zaragoza, Diputación General de Aragón, 149-152.

MURILLO, J. F.; LEÓN, A.; CASTRO, E.; CASAL, M. T. T.; ORTIZ, R., GONZÁLEZ A. J. (2010), «La transición de la Civitas clásica cristianizada a la Madina islámica a través de las transformaciones operadas en las áreas suburbiales», en D. Vaquerizo, D. y J. F: Murillo (Eds.) El Anfiteatro Romano de Córdoba y su entorno urbano. Análisis Arqueológico (ss. I-XIII d.C.), vol. 2, Córdoba, Monografías de Arqueología Cordobesa 19, 503-547.

MURILLO, J. F., CASTILlO, F., CASTRO, E., CASAL, M. a T., DORTEZ, T. (2010), «Los arrabales del sector septentrional del Yanib al-Garbi», en D. Vaquerizo, D. y J. F: Murillo (Eds.) El Anfiteatro Romano de Córdoba y su entorno urbano. Análisis Arqueológico (ss. I-XIII d.C.), vol. 2, Córdoba, Monografías de Arqueología Cordobesa 19, 565-615.

NAVARRO, J. (1995), Casas y palacios de al-Andalus. Siglos XII y XIII, El legado andalusí - Lunwerg Editores S.A.

- (2003), «Sobre la ciudad islámica y su evolución», en Estudios de arqueología dedicados a la profesora Ana María Muñoz Amilibia S .Ramallo(Ed.), Murcia, 319-381.

NAVARRO, J., JIMÉNEZ, P. (2007), Las ciudades de Alandalús. Nuevas perspectivas, Zaragoza, Instituto de Estudios Islámicos y del Próximo Oriente.

- (2007b), «Algunas reflexiones sobre urbanismo islámico», Artigrama 22, 259-298.

- (2011), «La partición de fincas como síntoma de saturación en la ciudad andalusí: los ejemplos de Siyasa y Murcia», en Varela R., Varela, M., Tente, C. (RRCC) Cristãos e Muçulmanes na Idade Média Peninsular. Encontros e Desencontros, Lisboa-Faro, Pórtico Librería, 79-94.

- (2009), «Casas y palacios de la Murcia andalusí a la llegada de Alfonso X», en Catálogo de la Exposición Alfonso X, Murcia, 705-720.

- (2009-b), «El poblamiento andalusí tras la conquista castellana», en Catálogo de la Exposición Alfonso X, Murcia, 726-739.

NAVARRO, J., JIMÉNEZ, P., GARRIDO, F. (2014), «Forma y función de la casapatio andalusí: Analogías y diferencias entre Murcia y Siyâsa (ss. X-XIII) », en Díez, M ${ }^{a}$ E. y Navarro, J. (eds.), La casa medieval en la península ibérica, Madrid, 335-391.

ORTEGA ORTEGA, J. M., GUTIÉRREZ GONZÁLEZ, F. J., PÉREZ-ARANTEGUI, J, DÉLÉRY, C. (2013), «La cerámica dorada en el NE de la Península Ibérica: las taifas de Zaragoza y Albarracín», Primer Congreso Internacional REMAI, Granada, 291-324.

PINON, P. (2001), «La transición desde la ciudad antigua a la ciudad medieval: permanencia y transformación de los tejidos urbanos en el Mediterráneo Oriental», en $\mathrm{La}$ ciudad medieval: de la casa al tejido urbano, (J. PASSINI Ed), Ier Curso de Historia y Urbanismo Medieval, Universidad de Castilla-La Mancha, Cuenca, 179-213. 
RÈKLAITYTE, I. (2012), Vivir en una ciudad de al-Ándalus. Hidráulica, saneamiento y condiciones de vida, Monografías Arqueológicas 47, Departamento de Ciencias de la Antigüedad de la Universidad de Zaragoza.

RIERA FRAU, M. (1998), «La ciudad islámica en las Islas Baleares», en Cressier, P., Garcia-Arenal, A. (eds) Génesse de la ville islámique dans l'Andalus et au Magreb Occidentale, Madrid, Casa de Velázquez-CSIC, 207-217.

ROSSELLÓ BORDOY, G. (2006), «De madina a ciudad: Mayurqa/Mallorques», en Al-Ândalus. Espaço de mudamça. Balanço de 25 anos de historia e arqueología medievais, Seminario Internacional en Homenaje a Juan Zozaya, 2005, Mertola, Campo Arqueológico de Mertola, 292-309.

RÜTENIK, T. (2009), «Transformación de mezquitas en iglesias en Toledo, desde la perspectiva de la arqueología arquitectónica», Anales de Arqueología Cordobesa, 20, 421-443.

SALVATIERRA, V., GARCÍA, J. A. (2001), «La reconstrucción del parcelario de las ciudades andalusíes. Las aportaciones de la documentación contemporánea», en La ciudad medieval: de la casa al tejido urbano, (J. PASSINI Ed), Ier Curso de Historia y Urbanismo Medieval, Universidad de Castilla-La Mancha, Cuenca, 33-50.

SOUTO, J. A. (1987), «Primeros resultados de una investigación sistemática en torno a la mezquita aljama de Zaragoza», Cuadernos de la Alhambra 23, Granada, 11-19.

- (1989), Textos árabes relativos a la mezquita aljama de Zaragoza, Madrider Mitteilungen 30, Madrid, 391-426.

- (1992), El poblamiento del término de Zaragoza (siglos VIII-X): los datos de las fuentes geográficas e históricas, Anaquel de Estudios Árabes 3, Madrid, 113-152.

- (2008 ), «La defensa militar de la Zaragoza omeya», Revista del Instituto Egipcio de Estudios Islámicos, Vol. XXXVI Zaragoza, Madrid, 87-111.

TORRES BALBÁS, L. [1971] (1985), Ciudades hispanomusulmanas, Madrid.

TORRÓ, J. «El urbanismo mudéjar como forma de resistencia. Alquerías y morerías en el reino de Valencias (siglos XIII-XVI) », en Actas del VI Simposio Internacional de Mudejarismo (Teruel, 16-18 de septiembre de 1993), Zaragoza, 1995, 535-598.

VALDÉS FERNÁNDEZ,F. (1998), «El urbanismo islámico de la Extremadura leonesa: cuatro pautas de desarrollo», en Cressier, P.; Garcia-Arenal, A. (Ed.), Genèse de la ville islamique dans l'Andalus et au Maghreb Occidentale, 159-183.

VAN STAËVEL, J.-P. (1995), «Casa, calle y vecindad en la documentación jurídica», en Navarro, J. (ed.) Casas y palacios de al-Andalus. Siglos XII y XIII, BarcelonaMadrid, El legado andalusí - Lunwerg Editores S.A. 53-61.

- (2001), «Influencia de lo jurídico sobre la construcción, análisis d’Ibn al-Imãn alTutili (Tudela, final del siglo X)» en La ciudad medieval: de la casa al tejido urbano, (J. PASSINI Ed), Ier Curso de Historia y Urbanismo Medieval, Universidad de Castilla-La Mancha, Cuenca, 215-239. 
VIDAL, F. (1995), «El agua en el derecho islámico. Introducción a sus orígenes, propiedad y uso», en Malpica, A. (ed.) El agua en la agricultura de Al-Andalus, Lunwerg, Barcelona, 99-118.

V.V. A.A. (1991), Las necrópolis de Zaragoza. Cuadernos de Zaragoza 63, Excmo. Ayuntamiento de Zaragoza.

YOUSSEF HOTEIT, A. (1993), Cultura, espacio y organización urbana en la ciudad islámica, Cuadernos de investigación urbanística n..$^{\circ}$, Instituto Juan de Herrera. 